\title{
Selective Carbon Material Engineering for Improved MEMS and NEMS
}

\author{
Stephane Neuville \\ Independent Consultant, F-77165 Cuisy, France; Steph.neuville709@orange.fr \\ Received: 3 June 2019; Accepted: 6 August 2019; Published: 16 August 2019
}

\begin{abstract}
The development of micro and nano electromechanical systems and achievement of higher performances with increased quality and life time is confronted to searching and mastering of material with superior properties and quality. Those can affect many aspects of the MEMS, NEMS and MOMS design including geometric tolerances and reproducibility of many specific solid-state structures and properties. Among those: Mechanical, adhesion, thermal and chemical stability, electrical and heat conductance, optical, optoelectronic and semiconducting properties, porosity, bulk and surface properties. They can be affected by different kinds of phase transformations and degrading, which greatly depends on the conditions of use and the way the materials have been selected, elaborated, modified and assembled. Distribution of these properties cover several orders of magnitude and depend on the design, actually achieved structure, type and number of defects. It is then essential to be well aware about all these, and to distinguish and characterize all features that are able to affect the results. For this achievement, we point out and discuss the necessity to take into account several recently revisited fundamentals on carbon atomic rearrangement and revised carbon Raman spectroscopy characterizing in addition to several other aspects we will briefly describe. Correctly selected and implemented, these carbon materials can then open new routes for many new and more performing microsystems including improved energy generation, storage and conversion, 2D superconductivity, light switches, light pipes and quantum devices and with new improved sensor and mechanical functions and biomedical applications.
\end{abstract}

Keywords: carbon-based material; carbon structure differentiation; NEMS quality; higher performances; revised Raman characterization; quantum electronic activation; carbon phase transition

\section{Introduction}

Although, micro, nano electromechanical and optomechanical systems are still often confronted to the lack of quality and longer life time and to the search of extended higher performances [1], huge progress has been recently achieved in MEMS and NEMS technology in using more performing carbon-based materials, which are presenting a large panel of various superior properties concerning their mechanical properties, such as young modulus, Poisson's ratio, fracture strength of nanocrystalline diamond for instance [2], tribological, electric, semicon, piezoelectric, heat conducting and optical/optoelectrical properties [3,4], diamond micro and nano resonators [5,6], piezo-resistivity obtained with carbon nanotubes [7], diamond-like carbon MEMS sensors [8] and many more which are making use of functionalized graphenic and related materials [9-20].

Key hurdles currently preventing the commercial application of many NEMS devices include low-yields and high device quality variability, concerning structure, physical and chemical stability, nucleation, adhesion, different kinds of internal and interface stress, tribology and wear rates, contamination diffusion barrier properties, stability and reproducibility of surface functionalization [16-19]. Before NEMS devices can actually be industrially implemented, reasonable integrations of carbon-based products must be created [21]. Next, the challenge to overcome is 
understanding carbon-based materials properties, with which efficient and durable NEMS with low failure rates can be achieved [22,23].

Basically, those can often be improved in using selectively different kinds of carbon materials including the different sorts of diamond, tetrahedral carbon, DLC, GLC, glassy carbon, nanowires and nanotubes and graphenic materials of specific properties [9] and we discuss that in more details in this study. Those have intrinsic properties, which are distributed over several order of magnitudes and have to be well distinguished from each other $[2,3,12,13,21]$.

Limiting factors of their implementation are generally a consequence of degraded structure and defects and possible induced phase transformation which are depending on their elaborating device and application environment $[23,24]$. It then appears necessary to also have all sorts of appropriate characterizing devices, which have to be used for the different process optimization steps. Further on it is then also to be considered well understood the aspects of surface preparation and processing, nucleation and growth mechanisms and especially the phase transformation they can be subject and which have been generally neglected and omitted to be considered although appearing of greatest importance [12,13,25-27].

Necessary mastering of differentiate carbon material depositing and characterizing can be achieved with recently revisited fundamentals on carbon atomic rearrangement [25] and carbon Raman spectroscopy [26]. In addition to several other revisited subjects, we briefly recall concerning diamond-like carbon coatings [27], energy storage and conversion using different kinds of carbon-based materials [28], superconductivity (because of some analogy with electron ballistic properties in graphenic materials [29], for which carbon materials need to be correctly selected and associated. This appears all the more important to be achieved, considering those, can open new routes for improved microsystems and 2D devices concerning mechanical functions, light switches, light pipes and quantum calculation devices [30].

\section{Brief Review on Main MEMS and NEMS Characteristics}

\subsection{Early Stage of Microelectromechanical Systems (MEMS)}

MEMS is the technology of microscopic devices, particularly those with moving parts smaller than a human hair with outstanding accelerating practical application interest during the last decades and which have rapidly achieved actuator dimensions in the $100 \mathrm{~nm}$ range, before becoming much smaller with nano-technologic means. They are now used for many applications, and a future form of NEMS is expected to exceed the IC industry in both size and impact on society [1].

These devices replace bulky actuators and sensors with a micron scale equivalent that can be produced in large quantities by the fabrication process used in integrated circuits. They reduce cost, bulk, weight and power consumption while increasing performance, production volume and functionality by orders of magnitude [21,23].

Those are concerning multidisciplinary fields in the areas of engineering, chemistry, material science, physics, and any specialized field for applications in bioengineering or medicine. Their future holds revolutionary breakthroughs in a wide range of: Nanocircuits, actuators (piezo-electrostatic, shape memory, electromagnetic), sensors, radar, locators, materials, imaging, nanocontact and nano-relays [31-41], micromotors and micropumps [42-49], optical functions and optoelectronic devices, such as switches, integrated energy harvesting, wave length filtering, optical grating switch and optical sensors-these MEMS are called micro optical electromechanical systems (MOMS) [50-52], energy storage [28,53], nanocapacitors, data storage and nano-computers $[1,30,54-56]$ including $2 \mathrm{D}$ superconducting devices to be used for quantum computers [29], and such as, bio-functionalizing, etc. $[1,11,16,57,58]$. 


\subsection{MEMS Fab}

MEMS became practical once they could be fabricated using modified semiconductor device fabrication technologies, normally used to make electronics. They usually consist of a central unit that processes data (the microprocessor) and several components that interact with the surroundings such as microsensors $[1,21,30]$. The fabrication of MEMS evolved from the process technology in semiconductor device fabrication, i.e., the basic techniques are the deposition of material layers, patterning by photolithography and etching to produce the required shapes and to which different types of bulk and surface micromachining of different materials can be associated [59-61].

The addition of specific material properties with the availability of inexpensive high-quality materials, and ability to incorporate electronic functionality make silicon attractive for a wide variety of MEMS applications. However, considering the large surface area to volume ratio of MEMS, and complex interface mechanical, chemical, electrical and electro-magnetic phenomena, their design requests particular attention and several other materials have been also considered for MEMS manufacturing, such as polymers, metals, and ceramics before considering advanced carbon materials [1,4-16] for many specific reasons on which we focus on in Sections 3-5.

\subsection{NEMS}

\subsubsection{Definition and General Features}

MEMS technology evolves into smaller nanoelectromechanical systems (NEMS) and nanotechnology [59-62]. These devices replace bulky actuators and sensors with a micron scale equivalent that can be produced in large quantities by the fabrication process used in integrated circuits in photolithography. They reduce cost, bulk, weight and power consumption while increasing efficiency, performance, production volume and functionality by orders of magnitude. They achieve a reduced size down to $10 \mathrm{~nm}$ range and less considering the size of some of their subsystems $[63,64]$. Miniaturization of MEMS fab could be achieved with two complementary approaches. (A) Top-down approach uses the traditional microfabrication methods. While being limited by the resolution of these methods, it allows a large degree of control over the resulting structures such as nanowires, nanorods, and patterned nanostructures are fabricated from metallic thin films or etched semiconductor layers [62]. (B) Bottom-up approaches, in contrast, use the chemical properties of single molecules to cause single-molecule components to self-organize or self-assemble into some useful conformation, or rely on positional assembly and allows fabrication of much smaller structures [63]. Those can be made at the VLSI scale, possibly co-integrated with CMOS well suited for autonomous, highly sensitive or dense sensors. They include complex gas portable recognition systems, mass spectrometry, or bio-sensors [11-14] and open several opportunities for integrated solutions in emerging domains as chemical analysis and life science $[16,21-24,30,57,58]$.

\subsubsection{Early NEMS Application Fundamentals}

Nanoscale mechanical sensors offer a greatly enhanced performance that is unattainable with microscale devices [59-67]: Ultrasensitive sensors [68], high quality factor diamond resonators [69], high mass and spatial resolution basing on mechanical resonance and cantilever vibration up to high frequencies [70], which is enabling chemisorption measurements in air at room temperature, with very high mass resolution below 1 atto-gram (10-18 g) [71]. Further on, high-sensitive liquid/airflow meter could be produced [72], nano ph sensor [73] and nano-molecular machines [74-80].

A molecular machine is a group of molecular components that are able to produce quasi-mechanical movements when exposed to specific stimuli.

There are three categories of the molecular machines, namely natural or biological, synthetic, and natural-synthetic hybrid machines [81-83]. Synthetic molecular machine includes motors, propellers, switches, shuttles, tweezers, sensors and logic gates. Biological motors convert chemical energy into linear or rotary motion as well as controlling many biological functions. Examples of linear motions: 
Proteins, muscle contraction, intracellular transport, signal transduction, ATP synthesis, membrane translocation proteins and the flagella motor. Natural-synthetic hybrid systems are mechanical motors inspired from DNA duplication and partition [83-88].

The NEMS technology is distinguished from molecular nanotechnology or molecular electronics in that the latter must also consider surface chemistry and solid-state phonon and electronic quantum mechanical aspects which can affect mechanical, electric and optoelectronic properties, friction and that can cause high signal/noise ratio ([89-92]. Mechanical deformation and electrical contact properties and adhesion between carbon nanotubes are important aspects of their quality and dynamic performances [93-98] and explaining why they must be selected and controlled upon their characteristics, size and defect content.

In spite of already numerous probated applications many potential others corresponding to bench lab prototypes could not yet be sufficiently mastered on their quality, reliability and life time in consequence of insufficiently understood fundamentals [21-23]. Among them, those concerning stability and material structure modification being induced by local quantum electronic effects which used to be ignored up to recent past $[25,99]$ and another important quantum mechanical revisited aspect concerning the characterization of carbon material: The recently revised Raman fundamentals with which carbon material structure and their defects can be better and more correctly sorted out [26] and we recall and discuss this in more details next in Sections 3-5.

Considering selective electronic activation of semiconducting surface material caused by adsorption and chemisorption and with which transversal polarization effects can appear [100], much sensitive and selective physicochemical interactions can be considered between nanoparticles and the biologic material. This is illustrated with size dependence of $\mathrm{Au}$ and Ag particle on different biological metabolism [101,102]. Different corresponding nano-effects are considered for nanomedicine and dentistry applications [103,104] and are also a subject of toxicologic investigations [105-107].

\section{Increased NEMS Performances with Advanced Carbon Material}

\subsection{Progress in NEMS Technologies}

They are less mature than that of MEMS due to the difficulty to reliably couple the micro-actuators to the macroscopic world and to achieve requested quality and performances, specially concerning longer life time, higher strength, better adhesion and tribology and better mechanical and chemical stability and better reproducible size, bulk and surface optoelectronic effects and heat/electric conducting properties [21-23]. However, owing to the use of different carbon-based materials with corresponding superior solid-state bulk and surface properties and which have been synthetized with more or less empirical means [3,10], the fast-growing number of MEMS/NEMS applications could be achieved. For instance, the scanning tunneling microscopes (STMs), inertial, pressure, thermal, optical, flow, capacitive position sensors, biochips for detection of hazardous chemical and biological agents, high-throughput drug screening and selection, optical switches, valves, RF switches, micro-relays, electronic noses, etc. $[1,44,45,61-65,74,108-110]$.

\subsection{Diamond and Related Materials}

\subsubsection{Different Categories of Diamond and Diamond-Like Materials}

Diamond materials offer great potential for electronic and biomedical application. With very high stiffness, high thermal conductivity, optical transparency range, chemical stability and wear resistance for the diamond-based materials extend their applicability for MEMS/NEMS [24]. Besides, these diamond materials which are nevertheless presenting a large panel of different structures and properties, and which have to be distinguished from each other's [3-68], many other different kinds of diamond-like materials have either to be considered and distinguished from each other's in so far they often present an underestimated wide range of specific combined properties. Those are depending 
on specific composite structure, defect, contamination and atomic disorder including physical and chemical, optical and optoelectronic properties, thermal, mechanical, chemical, tribological, and wear resistance, internal mechanical stress, electric properties and their possibility to be doped. Depending also, on their surface micro and nano rugosity, porosity and surface chemisorbing and adsorbing properties, and the way they can be produced [27,111-113]. Different categories of diamond and diamond-like carbon (DLC) materials have to be considered:

(a) Polycrystalline diamond of different crystallite size, including the hexagonal and epitaxial diamond. To be observed that the denser and smoother micro- and nano-crystalline diamond is almost containing a significant part of graphitic material where more or less ordered/disordered diamond crystallites are imbedded. However, besides interesting tribological properties, those have generally reduced others (optical, optoelectronic, chemical and mechanical) [114-119].

(b) Amorphous diamond and degraded tetrahedral amorphous carbon, ranging from materials with high internal stress such as the amorphous diamond and ta-C:H and others for which the internal stress could be reduced without graphitic degradation [120-126].

(c) Polymeric carbon $[127,128]$, although not being really diamond-like, but which contain many sp3 carbon chains and have a similar optoelectronic gap.

(d) Diamond-like $a-C: H$ and composite material such as diamond-like glassy-carbon CNx and sp3 rich carbon nanowire and fiber [24,27,129-133].

\subsubsection{Upholding of Combined Properties}

It must be emphasized that all these diamond and diamond-like materials have much different combined properties, concerning their Csp2 and Csp3 content, their thermal and chemical stability, and their simultaneous mechanical, tribological and optoelectronic properties. This is especially concerning the mechanical elastic/plastic/hardness properties which are obtained after an annealing process reducing the internal stress [3]. The resulting material will generally no longer combine higher diffusion barrier, optical and electric and/or dielectric properties. The harder homogeneous isotropic amorphous diamond combines many different superior interesting properties, except its electric conductivity and its internal stress which can only be annealed without degrading the initial properties with particular appropriate means (e.g., hard UV laser annealing) and when the temperature stays lower than the thermal graphitization temperature threshold [120-124].

When it is degraded to a more graphitic material, the amorphous diamond and harder ta-C will generally lose at least at nanoscale their amorphous homogeneity with the formed sp2 clusters (islands of sp2 material within the amorphous sp3 material). Then, they merely correspond to some nanocomposite material containing different adjacent phases and this is often leading to dramatic confusions between materials supposed to belong to the same category, whether being stress annealed or not and presenting important material structures and property differences [27,111-113]. Diamond-like carbon produced with non-optimized depositing equipment design and lower optimized depositing process or which is resulting from the thermal annealing of crystalline diamond and from highly stresses harder ta- $C$ has been often considered as an amorphous diamond, although being merely less hard, less homogeneous less smooth, less dense composite material with reduced optical properties and reduced thermal stability (in comparison to the diamond and harder tetrahedral amorphous carbon) [114-125].

To be observed that the temperature induced exodiffusion of hydrogen and other gaseous species can induce tensile stress and cracks [27]. This effect can be amplified when a graphitic material is transformed into a denser diamond-like material. These sorts of materials can be obtained with other means than combined pressure/heat and thermal spikes [111-124]. In such a case, contradicting effects have to be considered (either favorizing graphitization, or favorizing diamond-like structures) and which can be in competition to each other [25]. Those are suggested as explaining, for instance, why glassy carbon is not always showing graphenic properties, but can be 
harder and more diamond-like [132,133]. Similar effects have also to be considered for the growth of carbon nano-fibers of irregular cylindrical structure [134-136] and which in contrast to CNT are filled tubes containing also significant amounts of Csp3. For their accurate characterization, anticipating on the next chapter IV, revision of different characterizing such as Raman spectroscopy and interpretation appeared to be necessary and could helpfully be achieved [26].

\subsection{CNT and Graphene}

\subsubsection{Definition and Technologic Trends}

CNT corresponds to scrolled graphene sheets which are composed of juxtaposed hexagonal cyclic sp2 hybridization carbon atoms [13]. Since discovery in 1991 [3,137], carbon nanotubes (CNTs) have aroused a high amount of interest in their use as building blocks for many new applications based on outstanding mechanical properties [12] and which can be combined with their other interesting chemical and physical solid-state properties especially for various electrical, and opto-electronical devices and future integrated circuits due to their outstanding electrical, mechanical, thermal, opto-electric and solid-state combined surface properties $[138,139]$.

Improved performances achieved with several of their specific properties, are well illustrated with the development of carbon-based material field emissions beginning with a-C:H, improving with doped diamond and ta-C and achieving much more performing results with CNT, which are used for atomic force, scanning tunneling (STM) and magnetic force microscopy [140-145]. They could improve performances of catalytic nanomotors [146] and many new applications could be developed after controlling synthesis conditions, size (diameter/length) and structure (chirality, semi-conducting/metallic properties, single or multi-walled) $[147,148]$. However, many difficulties appeared for industrial application owing to contamination, defect and various still often little understood effects yet $[63,64]$ (such as rippling, and phase transformation) for which we propose some clarification next.

\subsubsection{Early Fundamentals on Graphene and CNT}

Solid-state quantum mechanical calculations could predict many electronic level and phonon modes distribution for a well-defined carbon material bulk structure, which elementary optoelectronic properties and Raman frequency could be determined especially for diamond, graphite and graphenic materials [117,149-151]. However, more complex often not well understood Raman spectra have been experimentally observed for thin film carbon materials containing different phases (carbon composite materials), which have been mainly used as spectroscopic fingerprints of corresponding materials. Those could be first used for the empiric observation of their structure modification and for which refined aspects give more precise information [113,137-139].

Considering some quantum electronic confinement effects for nano particles, very fine opto-electronic structure modifications are observed (Figure 1). This is especially the case for one and two-dimensional materials, which will be very sensitive to physical adsorbtion and chemisorption and to any bulk and surface structure modification [152-158]. 


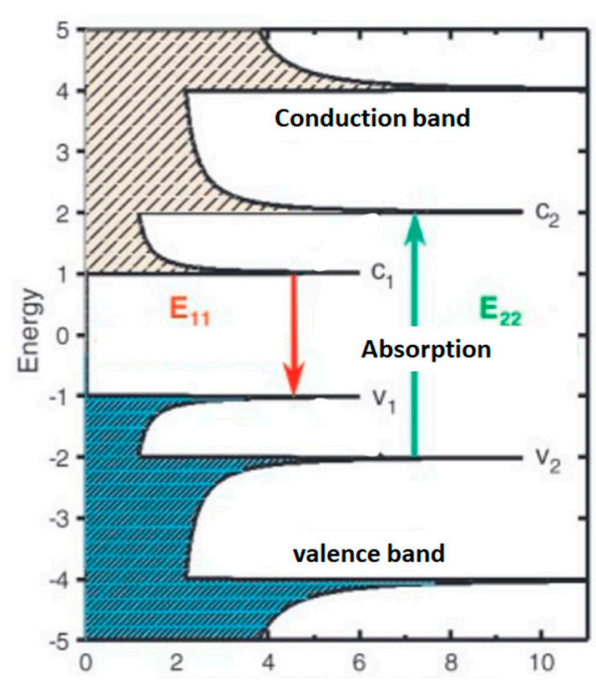

Figure 1. Scheme of optoelectronic band structure in single walled carbon nanotube by Bachilo et al. [158] reproduced with permission of the Journal of Science.

They can be functionalized and will offer, for instance, selective IR optical response to molecular adsorbtion $[159,160]$, which can be used, for instance, for selective photosensitive intrinsic polarimetry [161]. Additionally, improved electric conductivity can be obtained [162-164] with incorporation of iodine or copper, for instance, and also providing possible conduction anisotropy of expected interest for electric energy storage and antistatic encapsulating $[165,166]$. Very low resistivity is achieved with the electron ballistic transport effect, similar to superconductivity $[167,168]$ being actually well understood in using revisited description of super-conductivity with electron/phonon synchronic gating during which no electron/electron and electron/phonon scattering occur [29].

All these results will be also very sensitive to radiation damage [169] material contamination and defect content [149-151,170-172] (whenever with questionable conclusions we will discuss in next chapter) and which in addition, are also depending on specific material structure edge configuration and possible thermally induced modification [153-155] (as discussed in more details in Sections 5 and 6). However, interpretation and characterizing anomalies could be identified with the refined Raman theory [26], with which several observed contradicting aspects could be sorted out. Important new aspects of carbon phase transformation could especially be identified [25] with competing opposite effects that we believe can broadly explain the MEMS devices quality and performance distribution, which need to be comprehensively mastered and we briefly review next.

\section{Brief Review of Quantum Activated Atomic Rearrangement}

\subsection{Atomic Rearrangement during Synthesis of Carbon Materials}

\subsubsection{Graphitic Thermal Degradation and Diamond-Like Material Reforming}

Graphite being the ground state of carbon, any carbon material can be degraded to more graphitic material by thermal effects ruled by the Arrhenius law and with low energy thermal activation. This effect is observed during longer thermal annealing of diamond, DLC, a-C:H and glassy carbon $[3,15,27,111-117,129-131,173]$ below their sublimation temperature $\left(\sim 3500{ }^{\circ} \mathrm{K}\right)$ [174] (corresponding to $\sim 0.3 \mathrm{eV}$ electronic activation).

However, it is also known, that higher quantum electronic activation produced by different means and especially with photonic activation which can strongly influence chemical synthesis [175]. This is also the case during the formation of diamond and diamond-like material, which are not only formed with temperature/pressure and ionic thermal spikes producing compressive stress [111,112,124] but also with many other effects and without energetic ions (flame depositing, hot filament, high flux low ion 
energy, plasma jet, UV, X rays, electric neutralization energy, catalytic effects) $[25-27,119,122,176-180]$ and especially the chemical recombination energy release (CRER) of $\mathrm{C}-\mathrm{C}(\sim 7 \mathrm{eV}) \mathrm{H}_{2}(\sim 5 \mathrm{eV})$ and $\mathrm{N}_{2}$ $(\sim 12 \mathrm{eV})[25,121,181]$, which are exciting electrons with relatively high energies $(>1 \mathrm{eV}$ up to more than $10 \mathrm{eV}$ compared to thermal activation in the $\sim 0.1 \mathrm{eV}$ range) before producing phonons and heat, which can produce a noticeable higher quantity of rearranged sp3 material structure.

With Figure 2 we reproduce the Raman spectra from an N+ ion irradiated glassy carbon, which is transformed into a diamond like ta-C. To be observed that the annealing of CNx with a lower content of dissociated $\mathrm{N}$ will not produce the sp3 rearrangement effect because of insufficient N2 CRER activation events [182,183].

Updated Raman spectroscopy [26] shows that in many published thermal processing of carbon-based material supposed to produce graphitic material, in fact, resulting materials are also containing DLC, amorphous or nanocrystalline diamond [129-131,176,183,184] (what can be verified with measured sp2/sp3 obtained with electron energy loss spectroscopy and other more accurate, easy and fast XPS /Auger characterizing method, with which the measurement of the intensity of the Auger peaks of an XPS spectrum corresponding to Csp2 and Csp3 does not need any hazardous peak fitting assumptions and no deconvolution ) [27,120-123]. In such a case appearance of isolated diamond crystallites can correspond to increased abrasive friction. The diamond like phase transformation is also well documented, with a brief high temperature annealing of polymeric material that can be transformed into a diamond-like glassy carbon [132,133], meanwhile a longer annealing at higher temperature will produce a graphenic glassy carbon [133].

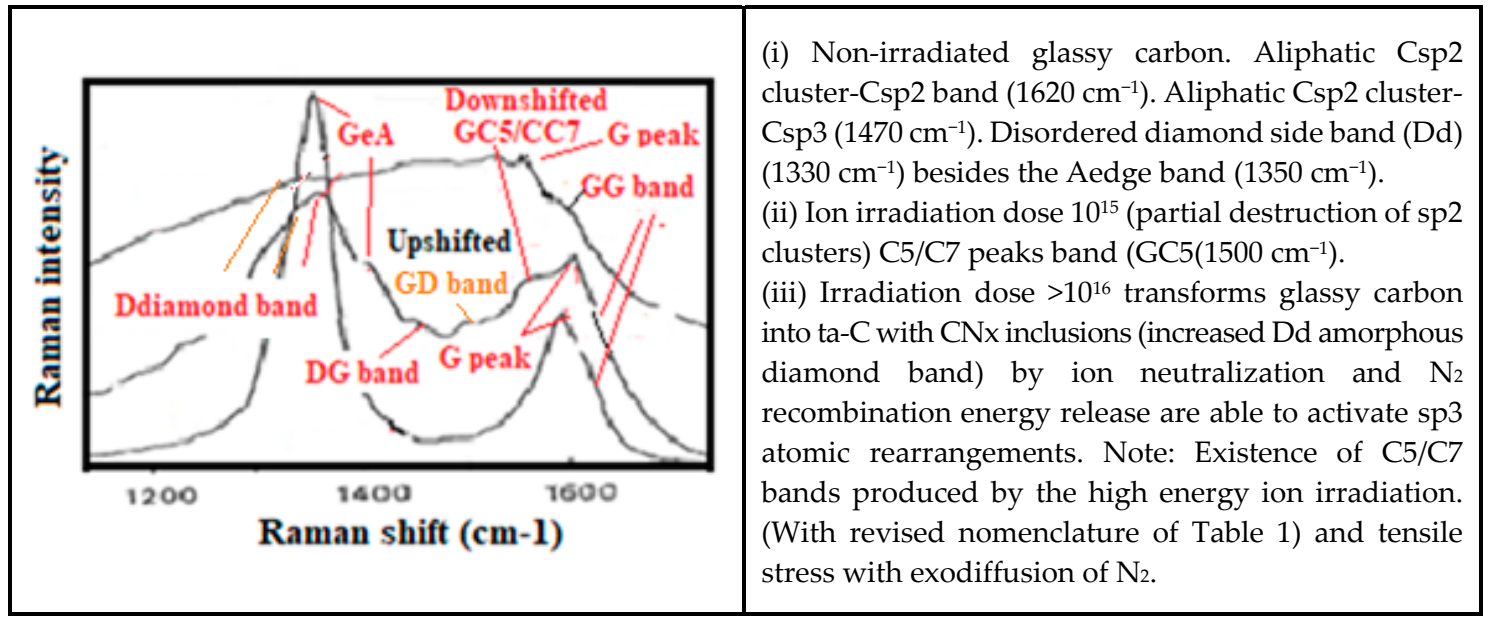

Figure 2. Glassy carbon $25 \mathrm{KeV}$ N+ ion irradiated with additional annotations from M. Iwaki et al. [182] with permission of the journal of J. Mater. Res.

\subsubsection{Surface Polarization and Diamond-Like Atomic Rearrangement}

It has been evidenced that adsorbtion energy can be directly transferred to the valence band electrons of the substrate, which after excitation are decaying with possible emission of corresponding photons of the same energy [185]. Thus, the adsorption of atoms and molecules on semiconducting material can produce electron/hole pairs and can produce a transient electric field (consequence of different mobility of electrons and holes being activated by released adsorbtion energy and which are then decaying [100]). In addition, it has been shown how an electric field transverse to a graphitic carbon thin film can enhance its sp3 content [186].

Above some electric polarization threshold energy, the carbon material can be transformed in a metastable material of higher density of cohesion energy. The hexagonal planar sp2 ring can be transformed in a buckled hexagonal chair plane (Figure 3) [25] (Similar to Silicene obtained with Si epitaxy on graphene [187], which is suggested to correspond to the caned structure of some carbon nanowires with irregular diameter [188]. 


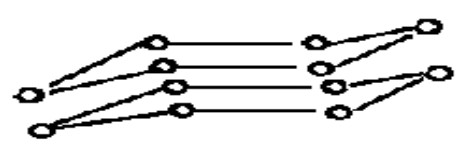

Figure 3. Transformation of graphene into H6 diamond with electric field polarization perpendicular to the graphene plane [25]. H6 diamond.: Stack of chair shape carbon hexagonal rings (sp3 bonded to four others). Raman frequency at $1325 \mathrm{~cm}^{-1}$ according to McNamara et al. [116] and Spear et al. [189] and Phelps et al. [190].

Most carbon material types have more or less a semiconducting electronic band structure and metallic CNT are in fact semimetal materials with valence band and conduction band [27,134,149-151,191]. Therefore, atomic rearrangement in consequence of more energetic electronic activation and formation of internal electric field with different decay time of activated electrons and holes (higher energy quantum electronic activation) can appear in many solid-state systems.

\subsubsection{Criterion of Quantum Electronic Sp3 Activation}

During an atomic rearrangement (Figure 4), the activated electron must always occupy authorized energy levels. Achievement of ordered atomic rearrangement can only happen with fulfilled conditions $[25,26]$ :

(1) Valence band electrons must be excited up to the conduction band of the initial and final state.

(2) More electrons must be activated than atoms to be rearranged.

(3) Atomic rearrangement can only be achieved with its local (proximity) activated electrons.

(4) The kinetic and density of activation events must be compatible with the decay and diffusion kinetic.

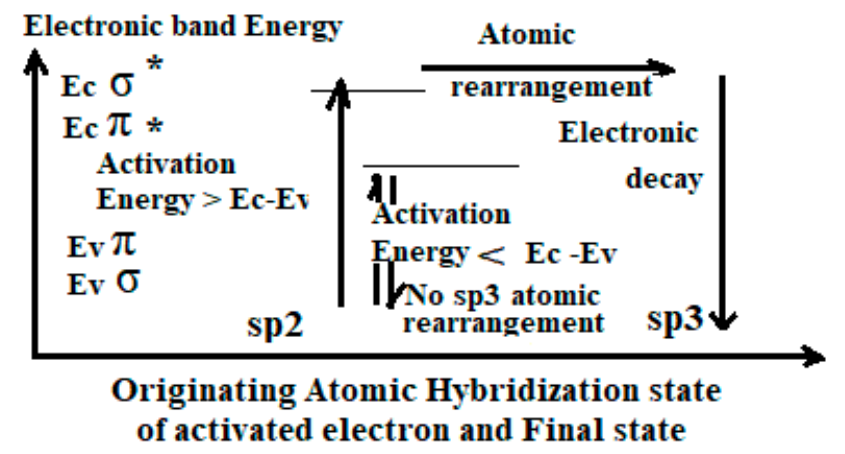

Figure 4. Principle of quantum electronic activated atomic rearrangement by S. Neuville [25].

\subsubsection{Ordered Atomic Rearrangement and Stress Modification}

Stress reduction is a major concern, in so far that internal stress can strongly affect adhesion and bulk diffusion [27]. Longer thermal annealing at a higher temperature produces graphitic degradation and stress relaxation, meanwhile a shorter thermal treatment of DLC, can reduce the stress without degrading the material as long as the limit of thermal stability has not been overpassed and the activation energy is not higher than the phase transition barrier potential $[25,27,111,133]$. This thermal stability depends on the structure of the carbon material $\left(\sim 900^{\circ} \mathrm{C}\right)$ for polycrystalline diamond [117], $\sim 600^{\circ} \mathrm{C} / 700^{\circ} \mathrm{C}$ for hard ta-C [121-125] and less than $200{ }^{\circ} \mathrm{C}$ during the ta-C growth, considering that the flux of energetic ions bombarding the growing film surface during an arc deposition generates additional heating [111] and local transient higher temperature than on the substrate holder.

At a higher temperature than the thermal stability limit, the material will be degraded into more graphitic material, unless a higher electronic activation is able to counterbalance the graphitization process and which can then enhance the diamond-like character of the considered material. For instance, 
during hard UV irradiation [122,176] and with chemical recombination energy release (CRER) of H in a growing diamond film $[25,192,193]$ and during glassy carbon synthesis, when the thermal process time did not exceed the time at which exo-diffusion of all hydrogen content has been achieved and the material has not yet be fully degraded to a more graphitic material [132,133].

With the exodiffusion of recombined $\mathrm{H}_{2}$ (or other gaseous material), tensile stress can appear [27,130]. However, uniformly distributed sp3 atomic rearrangement is generally forming higher packing density and stress relaxation, when no other effects such as thermal dilatation and/or ion peening is hampering this stress reduction process. This is typically achieved with catalytic sp3 rearrangement [194,195]. Catalytic effects produced with boron atoms can reduce $\mathrm{C}-\mathrm{H}$ binding energy and for which consequently the $\mathrm{H}_{2}$ and $\mathrm{C}-\mathrm{C}$ recombination energy release will be higher [25]. This explains why the added Boron in a high temperature diamond deposition process (where thermal dilatation can compensate the reduction of packing density) can produce better diamond quality in addition to the doping effect providing better electric conductivity [3,114,125,195].

\subsubsection{Examples of Diamond Like Atomic Rearrangement of Graphenic Material}

Several other illustrative examples can be cited for the diamond-like atomic rearrangement:

CNx Annealing with Formation of Diamond Crystallites

During the annealing of some CNx materials where larger amounts of $\mathrm{N}_{2}$ CRER can exist, many nano-diamond crystallites appear [181]. This is only achieved when many dissociated nitrogen atoms exist, otherwise only few $\mathrm{N}_{2}$ recombination events will be produced and at a higher annealing temperature the material will be degraded into some more graphitic material $[183,184]$.

\section{Graphene Transformation into a Dielectric Material}

Adsorbed hydrogen on graphene has been reported to convert highly electric conducting graphene into a dielectric buckled 2D planar graphane [196,197]. However, the existence of graphane is questioned with different arguments. The so-called No-Go criteria of the Landau phase transition theory [198] predicts that graphane cannot exist for thermodynamic reasons. This effect appears to be very important to be accurately sorted out for many CNT/graphene NEMS applications.

On a graphene surface, $\mathrm{C}-\mathrm{H}$ bonds are expected to be formed only on external graphene flake edges or on internal edges of voids and vacancies where dangling bonds exist, considering that the $\mathrm{C}-\mathrm{H}$ bond energies (between 4 and $4.5 \mathrm{eV})$ is lower than the $\mathrm{H}_{2}$ binding energy $(\sim 5 \mathrm{eV})$ and much lower than the graphene or diamond $\mathrm{C}-\mathrm{C}$ bond energy $(\sim 7 \mathrm{eV})$. Whenever the existence and stability of graphane was predicted by theoretic calculation [199], the question will be how this material can be formed, considering the low adsorption energy of the $\mathrm{H}_{2}$ molecule on a graphene surface and the low chemical reactivity of graphite and graphene for many chemical compounds (such as $\mathrm{Cu}$ etc.).

Considering the low adsorbtion energy on a defect free graphene surface, $\mathrm{H}_{2}$ molecules have a high surface mobility, except on the graphene defects (vacancies, voids, Smith Wales defects -C5/C7 odd sp2 ring pairs [200] where adsorbed $\mathrm{H}_{2}$ can be transformed in local $\left.\mathrm{C}-\mathrm{H}\right)$. Considering that $\mathrm{H}$ can easily recombine to $\mathrm{H}_{2}(\sim 5 \mathrm{eV})$, the formation of alternating the $\mathrm{C}-\mathrm{H}$ bond $(\sim 4.3 \mathrm{eV})$ on each graphene flake face will be unlikely. However, with the high $\mathrm{H}_{2}$ recombination energy release graphene can be transformed into a buckled H6 diamond (according to Figure 3) with enough available activation events and in agreement with observed formation of Csp3 [197] and looking in more details to the corresponding Raman spectra, with a Raman peak H6 structure at $1325 \mathrm{~cm}^{-1}[199,200]$. It can be observed that high pressure $\mathrm{H}_{2}$ on a graphene surface, can hardly be dissociated except on defects where dangling bonds exist, explaining why only local diamond structure can be expected [201].

\section{Transformation of Graphene into H6 Diamond with N and O}

Another demonstrative experiment suggests that graphane cannot exist. This is given when a similar transformation of graphene into a dielectric material with other atoms than hydrogen, and also, 
which is observed with nitrogen and oxygen. Quantum electronic activation can be produced with the $\mathrm{N}_{2}$ recombination energy release, similarly to what can be produced during some $\mathrm{CNx}$ annealing as precedingly reported [181] with the formation of diamond crystallites. The phase transformation can be enhanced in comparison to a similar experiment with $\mathrm{H}$, because the $\mathrm{N} \equiv \mathrm{N}$ recombination is releasing higher energy $(\sim 12 \mathrm{eV})$ than the $\mathrm{H}_{2}$ recombination and because the $\mathrm{C}-\mathrm{N}$ bond energy $(\sim 3.16 \mathrm{eV})$ is weaker than $\mathrm{C}-\mathrm{H}(\sim 4 \mathrm{eV}$ up to $4.5 \mathrm{eV})$ [25]. Binding energy differences of $\mathrm{N}_{2}, \mathrm{C}-\mathrm{C}$ and $\mathrm{C}-\mathrm{N}$ also explain in contrast to the early quantum mechanical calculated prediction [202] why the c- $\mathrm{C}_{3} \mathrm{~N}_{4}$ formation is unlikely (because the $\mathrm{C}-\mathrm{C}$ and $\mathrm{N}_{2}$ bond energy are much higher than $\mathrm{C}-\mathrm{N}$ ) and why this virtual material cannot be harder than diamond considering the equivalence of hardness with the density of cohesion energy [27].

However, graphenic $\mathrm{G}-\mathrm{C}_{3} \mathrm{~N}_{4}$ can be formed with the substitution $\mathrm{N}$ during a graphitization process and with the assembling of $\mathrm{CN}$ radicals. A material which is thought to be suitable for photo-catalytic $\mathrm{H}_{2}$ production from water [203]. However, we suggest that similar conditions can be expected with the same optoelectronic gap with more stable material corresponding to doped ta-C-like material, and also, which can combine the appropriate gap, electric conductivity and enough thermal/chemical stability.

\section{Oxygen Sensitivity of CNT Electric Conductivity}

Strong sensitivity to the oxygen environment of CNT appears to be a major problem to be solved for many NEMS applications [204]. Anticipating on the next Sections 4 and 5 and in making usage of the revisited Raman spectroscopy, very demonstrative experiments with oxygen plasma etching of multilayer graphene are showing how on nearly defect free graphene sheets (no Raman C5/C7 band and no D peaks of any kinds) an important part of the graphene multilayer is transformed into an $\mathrm{H} 6$ diamond [205] and optoelectronic and electric conducting properties will be significantly modified. For such case the CNT cylindrical geometry is preserved because diamond structure islands are only formed on vacancies and around void edges.

\subsection{Importance of Diamond-Like Phase Transformation on Carbon Material Properties}

\subsubsection{Phase Transformation and Internal Stress Formation}

Rapid and strong phase transformation toward atomic denser packed material can induce tensile stress before forming cracks, all the more this effect can be enhanced with the exodiffusion of lose bonded gaseous material $\left(\mathrm{H}_{2}\right.$ or $\mathrm{N}_{2}$ or $\mathrm{CH}_{4}$ as observed for instance with the synthesis of porous glassy carbon). This is also observed during the annealing of some H-rich a-C:H or N-rich CNx materials $[130,131,177]$ when some denser packed material can be formed containing diamond crystallites and for which higher friction can appear.

This sort of mechanism is suggested to explain how energetic UV will destroy graphene and CNT when these materials are subject to phase transformation toward isotropic denser packed sp3 with formation of cracks [206]. An effect which is also concerning metallic alloys, which can become brittle with cracks formation when incorporated hydrogen recombines to $\mathrm{H}_{2}$ and this effect is the consequence of different structures with different atomic packing density (corresponding to different oxidation states), which are also used in aeronautical and nuclear metallurgy [207].

\subsubsection{Incidence on Carbon Film Nucleation}

Vacuum film nucleation is generally produced with disordered randomly distributed condensation, surface migration and cluster formation before being coalescent. If strong interlayer bonds are formed on the substrate surface or on the growing material surface, then surface migration is hampered and the structure of this first layer will be generally amorphous with reduced atomic packing density, especially when the growing film material is subject to ion bombardment which is heating the growing material and which will keep atomic disorder [208] except if the epitaxial order can be imposed and/or 
if the material can be activated towards better crystallinity. The first grown atomic layers is generally graphitic either amorphous or recrystallized in the form of Csp2 clusters depending on the achieved surface mobility of the condensing atoms on the substrate. This surface mobility can be very low in the case of strong bond formation corresponding either to diamond materials $(\sim 7.02 \mathrm{eV})$ or to graphenic materials $(\sim 7.03 \mathrm{eV})$.

However, nucleation of the diamond material appears where the chemical recombination energy release (CRER) activation is sufficiently available, which can be produced in larger quantities with different means: In the grooves of the substrate surface after scratching [25], which can be enhanced when instead of $\mathrm{SiC}$ bonds, higher energy $\mathrm{C}-\mathrm{C}$ bonds can be formed and all the more, when clean contaminant free epitaxial conditions exist [111]. This is the case also, for heteroepitaxial conditions when additional activation energy can be delivered. For instance, with the diamond growth on an activated carbon pretreated crystalline molybdenum [119]. (This is no longer observed after decay of the surface activation) [111].

Graphene can be formed on a substrate with high surface mobility of condensed carbon atoms, which will have reduced adhesion on the substrate [13,172]. Meanwhile, single walled carbon nanotubes can nucleate on some catalytic substrate, with which some activation (much lower than necessary to produce diamond) will determine radius and chirality of the CNT $[13,150]$.

Defects on the substrate, contamination and temperature can modify nucleation conditions and the adhesion of the growing material. The formation of interface bonds with higher binding energy on defect edges and causing electron excitation with released recombination energy, may produce some phase modification towards denser material structure, stress and additional defect formation [15,150-153]. Discontinuities, defects, vacancies and voids will be important to consider, when on their edges strong interface bonds can be formed, contrary to chemically neutral defect free graphenic surface.

\subsubsection{Incidence on Carbon-Based NEMS Engineering}

All precedingly mentioned effects concerning phase transformation, adhesion, heat and electric conductivity, and also, which are depending on the type, size and number of defects are expected to cause major problems in industrial implementations of NEMS [10,13-15,21-24,63,64,147,148]. They will affect the life time and many opto-electronic and sensor functions, friction, wear, geometric tolerances, adsorbtion and mechanical properties.

Therefore, the principle of these effects must be well understood and correctly characterized. In all cited cases, it appears important to know and to master the types and number of defects and for which many interpretations will have to be revisited with all newly discovered effects, which need to be considered and to be correctly characterized, and what we discuss next.

\section{Brief Review of Revisited Carbon Raman Spectroscopy}

\subsection{General Aspects of Carbon Raman Spectroscopy}

The Raman spectroscopic assignment and interpretation still present in the literature of many confusing and contradicting aspects need to be sorted out. Carbon materials are often more composite than originally assumed and for which persisting grave lacks on Raman fundamentals must be cured. A distinction must be made between the $D$ diamond that peak normally at $\sim 1330 \mathrm{~cm}^{-1}$ and the so-called D-disorder peak which is normally at $\sim 1350 \mathrm{~cm}^{-1}$ when no stress-shift applies. It must be determined which stress is to be considered and to which substructure the observed Raman band corresponds (Figure 5) [208,209]. 


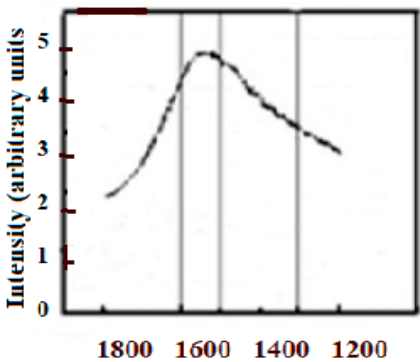

(a)

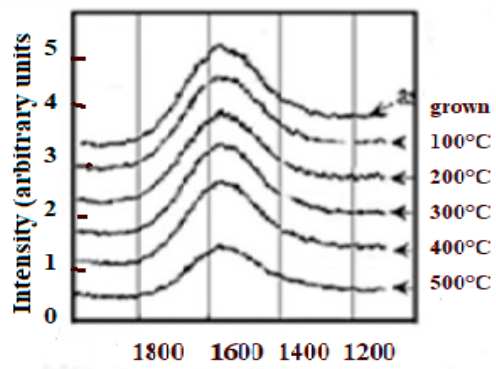

(b)

Figure 5. Raman spectra of stress shifted amorphous carbon graphitic carbon, ta-C and degraded ta-C (DLC) with no Csp2 clusters (no G sharp peak). Band max corresponding to (overlapping bands neighbor to the $G$ peak at nominal $1580 \mathrm{~cm}^{-1}$ ). (a) Tensile stress $\sim 30 \mathrm{~cm}^{-1}$ downshifted spectrum of amorphous graphite by Rouzaud et al. [208] by permission of the journal of Thin Solid Films. Additional dangling Csp2-Csp2 and C5/C7 bands. (b) Compressive stress $\sim 80 \mathrm{~cm}^{-1}$ upshifted spectra of ta-C thermally degraded to less hard ta-C with reduction of stress. By Anders et al. [209] by permission of the Journal of Thin Solid Films.

The analysis of the Raman spectra contrary to popular belief [210,211], cannot be limited to the sole measurement of the peak intensity and width of the respective so-called D and G bands [27,111-117,147-151,170,171,210,211], except when the material is either polycrystalline graphite [212] or diamond-like pure $[113,173]$ (containing only sp3). This is well shown with Raman spectra, which have been recorded during a diamond annealing process, with which different peaks and bands appear, corresponding each of them to some specific substructure (Figure 6) [117]. Contrary to the elder persisting popular belief the sp2/sp3 ratio and the diamondlike character of carbon will generally not be able to be deducted from the ID/IG ratio [27].

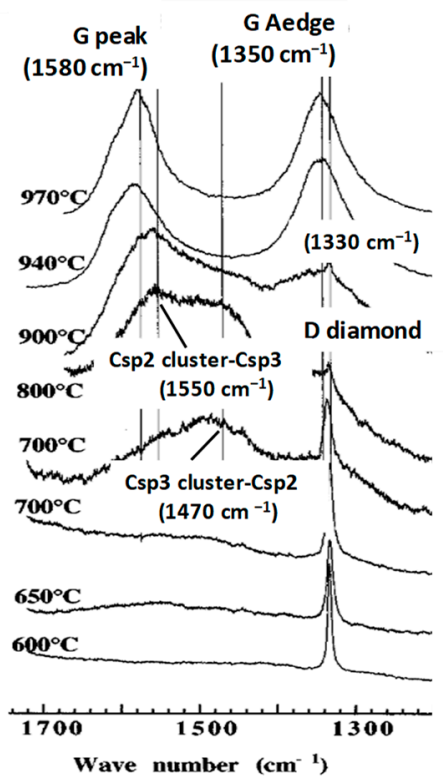

Figure 6. Diamond degradation with temperature by L. Fayette et al. [117] with permission of the Journal of Physical Review B. The D diamond peak decreases meanwhile Csp3-Csp2, G and G A edge peak are growing. 


\subsection{Carbon Structures to Be Considered with Raman Spectroscopy}

\subsubsection{Comparison of Raman Spectra from Different Carbon Materials}

Different Raman peaks corresponding to different carbon material structures have been calculated with theory $[189,190]$ and in agreement with experimental results from: (a) Micro-crystalline and amorphous diamond [116,173], (b) degraded variants and diamond-like carbon containing different kinds of subdomains [111,115,117,125,181]: Amorphous sp2/sp3 mixture, and amorphous/nanocrystalline sp3 parts) $[130,173,209,210]$ (d) deformed sp2 clusters, graphene planes and graphenic fibers and tubes [134,150,151], (e) glassy carbon (porous mix of fullerenic GLC, graphenic material, diamond-like material and H6 hexagonal diamond) [111-113,132,133] and for which persisting confusion in literature needs to be sorted out.

The Raman spectra of carbon materials that are supposed to be different, can show a paradoxical similitude for instance between the ta-C and amorphous graphite (Figure 5) or between the micro-diamond [115] and glassy carbon [132,133] (as shown in Figure 7). However, the stress shift must be considered in order to correctly assign the considered peak (or band). In Figure 6, the band maximum will not correspond to a shifted $G$ band (which is normally at $\sim 1580 \mathrm{~cm}^{-1}$ ), but to a band which normally would be observed at $\sim 1500 \mathrm{~cm}^{-1}$ and which corresponds to a Csp3cluster-Csp2 band [25].

The $\mathrm{D}$ band designation had been extrapolated from the Raman peak of the single crystal diamond with a similar frequency (whenever different) and which contrary to elder belief is not always giving account for the sp3 concentration [26]. Proportionality to the sp3 concentration is only given when the carbon material is corresponding to totally mono- or poly-crystalline and to amorphous diamond materials [113,124,126,173]. For GLC (graphite like carbon) IG/ID has been shown (by Tuinstra and Koenig) to be proportional to the graphite crystallite size and surface/volume ratio [213] and which can be corroborated by the optoelectronic gap dependence on number of adjacent hexagonal cyclic sp2 rings [214].

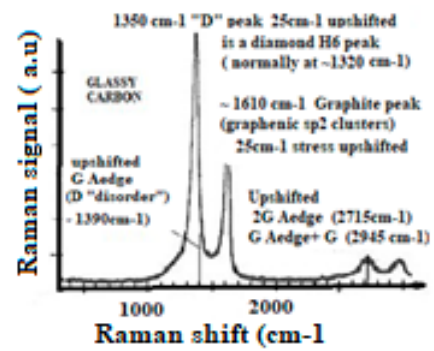

(a)

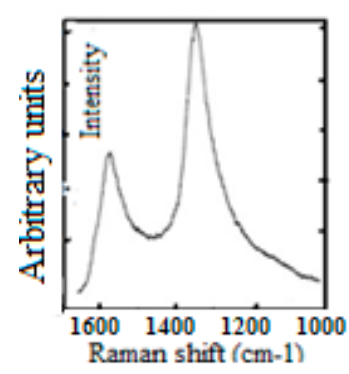

(b)

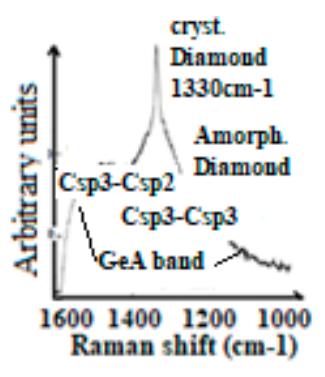

(c)

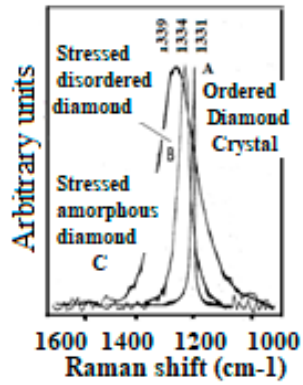

(d)

Figure 7. Comparison of Raman spectra of carbon materials that are supposed to be very different. (a) Glassy carbon $\left(25 \mathrm{~cm}^{-1}\right.$ stress up-shift) by Badzian et al. [132] with permission of Les Editions de la Physique. Glassy Carbon (GC) is not always graphitic. In the present case, ordered Diamond H6(sharp up-shifted peak at $\left.\sim 1350 \mathrm{~cm}^{-1}\right)$. Upshifted G peak $\left(\sim 1610 \mathrm{~cm}^{-1}\right)$. Upshifted Ddisorder (GeA) $\left(1370 \mathrm{~cm}^{-1}\right)$ and $\mathrm{G}+\mathrm{GeA}\left(2945 \mathrm{~cm}^{-1}\right)$. Note similitude with b. (b) Diamond crystals imbedded in graphenic matrix by McNamara et al. [116] with permission of the Journal of Diamond and Related Materials. G peak, D diamond broad peak superimposed on GeA band (so-called D disorder band), (c) Superimposed D diamond peak with D diamond band and GeA band by Mc Namara et al. [116] showing existence of DG band $\left(\sim 1450 \mathrm{~cm}^{-1}\right)$ and DD band $\left(\sim 1140 \mathrm{~cm}^{-1}\right)$ with permission of the Journal of Diamond and Related Materials.. (Necessity of differentiating the D designation. (d) Comparison of (A) ordered diamond (B) disordered diamond (C) amorphous diamond broader peak (B) and (C) with stress shift by P.H. Huong et al. [173] with permission of the Journal of Diamond and Related Materials. 


\subsubsection{Raman Stress Shift and Atomic Disorder Band Broadening}

It was generally admitted that a Raman D peak in graphenic materials containing no sp3 sites would correspond to the atomic disorder $[112,170,208-210]$ and an assignment which can be questioned in taking into account following considerations

The disordered material has distributed an interatomic distance explaining the Raman peak broadening [26], considering interatomic energy potential $U=\alpha x^{6}$ and binding force $B f=2 \alpha x^{4}$ and internal stress (which affects the interatomic energy potential) $[215,216]$ it can be deducted:

$\delta \omega / \omega_{0}=\eta . \delta x / x_{0}(\eta$ a proportionality factor, $\omega$ the Raman frequency and $\delta x$ the interatomic distortion to the ordered material interatomic distance $x_{0}$ and with $\delta \omega / \omega_{0}=6(1-v) / E_{0}(v$ Poisson coefficient, $\mathrm{E}_{0}$ the mean elastic and 6 the stress). Therefore:

(a) Sharp Raman peak corresponds always to an ordered structure.

(b) Atomic disorder corresponds to peak broadening

(c) Raman shift is proportional to internal stress.

This suggests incoherent and confusing designation between the so-called D diamond and so-called "Ddisorder" band which appears necessary to be sorted out. It must first be taken into account that the stress shift of Raman frequencies is of greatest importance to be considered in order to avoid possible confusion between neighbor carbon Raman peaks.

A Raman peak/band might be erroneously assigned when the relevant local stress shift has been ignored. Additionally, awareness of possible atomic rearrangement may help to sort them out.

The relation between some so-called D and D' disorder peaks and atomic disorder in a graphene plane has been proposed with a study on defect formation in a graphene plane [170] (Figure 8).

However, such a disorder is only appearing for larger ion doses for which the graphene material is amorphized and hexagonal cyclic rings specific to graphene will be almost destroyed, meanwhile is to be emphasized that the appearing sharp so-called "D disorder" peaks correspond to well defined frequencies and which can only be associated to well-ordered material structure. Therefore, suggesting that this "D disorder" peak is associated to void formation with Ar ion impact, which has perforated the graphene sheet and void internal edges have been formed.

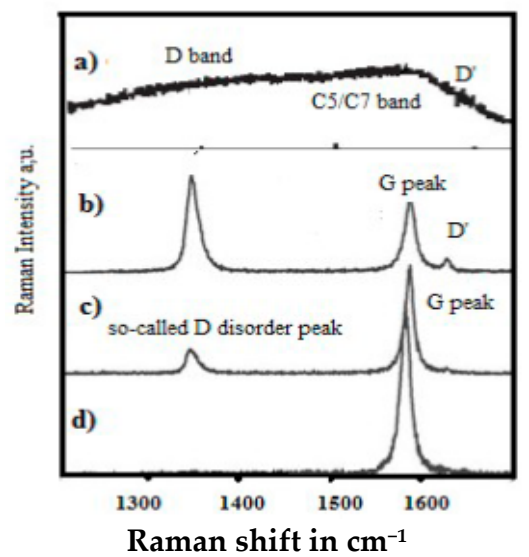

Figure 8. Relation between graphene void defects produced by Ar ion bombardment and so-called D disorder carbon Raman peak. By M.S. Dresselhaus et al. [170] with permission of Phil. Trans. R. Soc. A. (a) With Ion dose $>10^{15}$ destruction of hexagonal ring. Disorder band broadening, with $\sim 30$ $\mathrm{cm}^{-1}$ stress shift. The broad " $\mathrm{G}$ " band corresponds to the upshifted band of $C 5 / C 7$ odd rings. (b) $\mathrm{D}^{\prime}$ peak suggested to be assigned to dangling Csp2-Csp2 formed on internal void edges. (c) For ion dose $10^{11}$ the $\mathrm{G}$ peak is stress upshifted, without disorder band broadening, suggesting few incorporated vacancies. (d) Pristine graphene is an ordered structure (one sharp G peak). 


\subsubsection{Raman Peak Designation and Atomic Disorder}

With the temperature annealing of some polycrystalline diamond film showing a single intense D diamond peak, a polycrystalline graphite structure appears with several peaks corresponding to specific subdomain structures for intermediate states of the graphitic degrading process [117].

Sp2 clusters and graphite crystallites are growing in number and size, meanwhile the diamond polycrystalline structure is reduced.

Csp3-Csp3 and Csp3-Csp2 dangling bonds appear on diamond crystallite edges and boundaries corresponding to the transition to graphitic clusters and graphite crystallites. Thus, also, Csp2-Csp3 and Csp2-Csp2 dangling bonds will appear on graphitic particle edges and boundaries (Figure 6) $[25,117,210]$. The D peak is growing, although the material is becoming graphitic and the sp3 content is decreasing, and the higher content of sp2 and graphenic particles have appeared. Obviously, this growing "D" peak is different from the $\mathrm{D}$ diamond peak and used to be called the "D disorder" peak, although no disorder peak broadening is to be considered.

With thermal annealing of some particular CNx and a-C:H [130,181] (Figure 9) for which graphite recrystallization would have been expected, it can be observed as a similar spectra than for the polycrystalline diamond [115,116] (Figure 7) (with a G peak for sp2 clusters inclusions) and similar, as well to some glassy carbon [132]. Here, a D peak/band $\left(\sim 1325 \mathrm{~cm}^{-1}\right)$ is superimposed on a D disordered/amorphous diamond band and on a broader "Ddisorder" side-band, before being converted into graphite (carbon ground state) $[113,130,211]$. With a $500{ }^{\circ} \mathrm{C}$ longer annealing ( $1 \mathrm{~h}$ range) any stress is reduced and all observed Raman peak frequencies correspond to their nominal assignment.

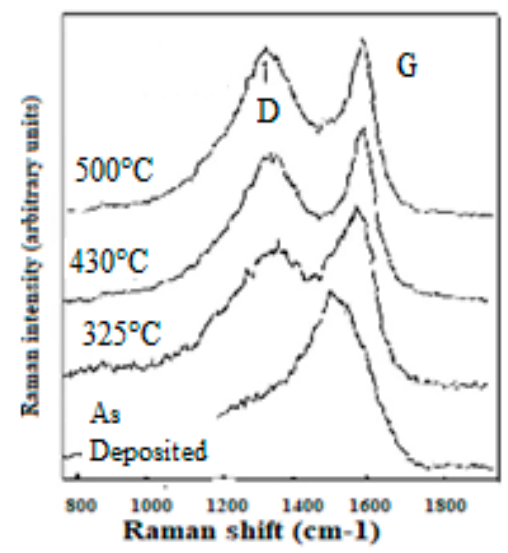

Figure 9. Annealing of $\mathrm{H}$ rich a-C:H. As grown, a-C:H $70 \mathrm{~cm}^{-1}$ tensile down shift owing to $\mathrm{H}_{2}$ exodiffusion. With annealing, stress is reduced and Csp2 clusters grow (G peak) A GeA band (Csp2 cluster edge) appears beside a growing diamond peak $\left(\sim 1325 \mathrm{~cm}^{-1}\right)$ (an $\mathrm{H} 6$ diamond). By Wagner et al. [130] with permission of Les Editions de la Physique.

\subsection{Revision Necessity of Common Raman Scattering Description}

Raman spectroscopy is widely used for graphenic material characterizing [217]. No so-called "D disorder" band is observed for the bulk of large graphite particles [117,212], in contrast to graphite dust [212] suggesting that the so-called "D disorder" peak corresponds to some edge effect.

This is clearly evidenced with the high-resolution micro-Raman [154,155] (Figure 10) showing that the phonon vibration mode of the so-called Raman "D disorder" peak $\left(\sim 1350 \mathrm{~cm}^{-1}\right)$ has a specific locality on the A edge, meanwhile this Raman peak does not appear on the ZZ edges. For some kinds of defect free bulk graphene, no D peak exist $[170,218,219]$ meanwhile an intense 2D peak can be observed (Figure 11), depending on how the graphene was elaborated (many different elaboration processes exist today) $[13,220,221]$. 


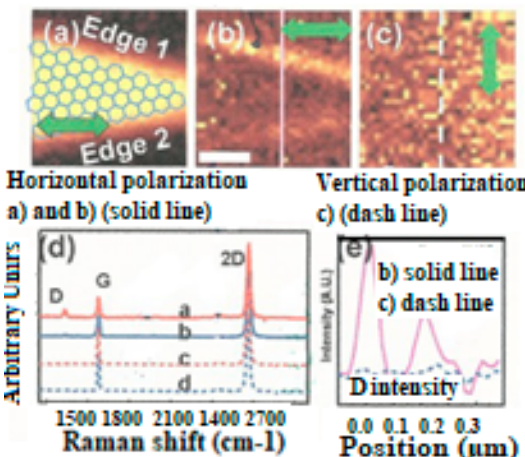

(A)
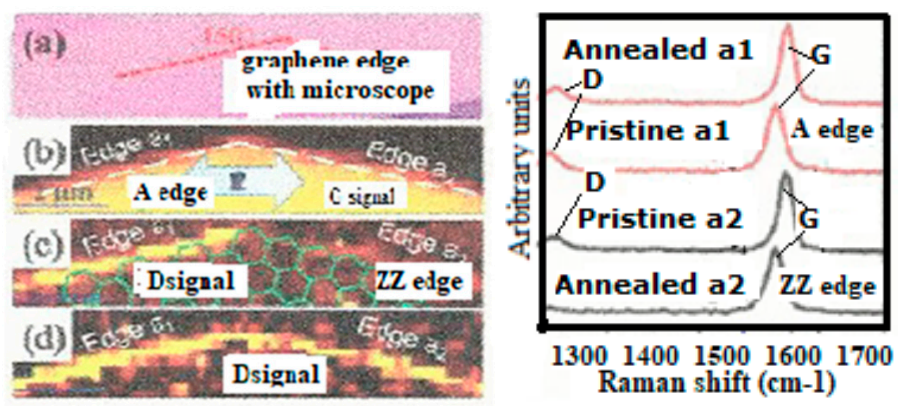

(B)

Figure 10. Micro-Raman showing locality on graphene A edges of the so-called D disorder Raman band. (A) Micro-Raman of graphene by Y.M. You et al. [154] with permission of Applied Physics Letters, Image of: (a) G peak, (b) "D disorder" peak (GeA peak) only on the A edge (c) GeA peak with vertical laser polarization. No D' peak and C5/C7 band (no disorder). (d) Raman spectra on bulk. (e) Raman intensity geometric distribution of D signal (B) Micro Raman spectra showing graphene ZZ edge transformation into the Aedge with thermal annealing at $300^{\circ} \mathrm{C}$ adapted from Y.N. Xu [155] with permission of the ACS Nano. No C5/C7 band at $\sim 1500 / 1530 \mathrm{~cm}^{-1}$. Pristine non-annealed graphene shows tensile downshift of $\sim 20 \mathrm{~cm}^{-1}$ indicating that it was prepared by CVD. Stress disappears with annealing temperature at $\sim 300{ }^{\circ} \mathrm{C}$. (a) graphene edge location, (b) Image of $\mathrm{G}$ peak on bulk, (c) Image of $\mathrm{D}$ peak only on A edge after annealing, (d) Image of D peak on pristine graphene flake.

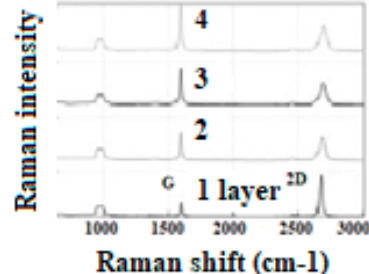

(a)

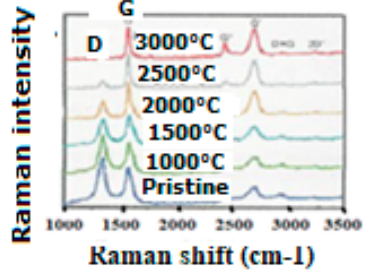

(b)
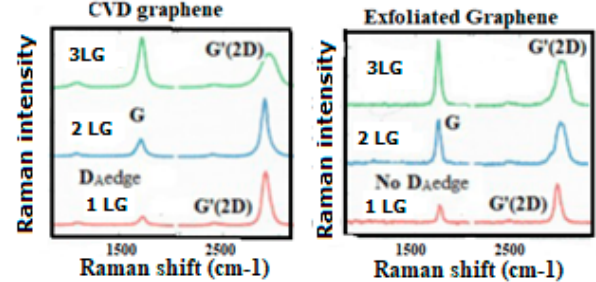

(c)

Figure 11. Raman spectroscopy of different quality of graphene. (a) High temperature longer time annealed graphene by Watanabe et al. [218] with permission of Diamond and Related Materials. No GeA peak (so-called "D disorder"). (b) Annealed graphene by J. Campos Delgado [172] with permission of Chemical Physics Letters suggesting many defects left, even after annealing. (c) Raman spectra by A. Reina et al. [219] with permission of Nano letters, showing no D disorder peak (GeA), sharp 2D and $\mathrm{G}$ on $1 \mathrm{~L} / 2 \mathrm{~L}$ indicating reduced disorder for the exfoliated graphene and some disorder for the CVD graphene with broader G and G' (2D) sheet without C5/C7 ring formation.

The Raman analysis and scheme of cut graphene (Figure 12) [222] can bring clarification on the corresponding structure of the so-called D'disorder band, considering that the Raman frequency for Csp2-Csp2 dangling bonds is the same than that for their IR stretching mode at $\sim 1620 \mathrm{~cm}^{-1}$ and that such dangling bonds are likely existing after a graphene plane cut and noticing that the cutting process can involve compressive stress in the resulting edge structure [223].

However, in order to know more accurately the carbon structure of the material it is necessary to know to which structure the D peak corresponds and to consider the different types of subsystems including Csp3-Csp2 $\left(\sim 1520 \mathrm{~cm}^{-1}\right.$ and $\left.\sim 1470 \mathrm{~cm}^{-1}\right)$ [26,117,182], Diamond edge Csp3-Csp3 bonds ( often designated $\mathrm{T}$ band) $\sim 1100 \mathrm{~cm}^{-1}$, H6 sp3 hexagonal Diamond $\sim 1325 \mathrm{~cm}^{-1}$, D crystalline diamond/D amorphous diamond band $\sim 1330 \mathrm{~cm}^{-1}[26,113,173]$. Edge dangling bonds Csp2-Csp2 (so-called D' peak) $\sim 1620 \mathrm{~cm}^{-1}$ ) [170,222,223] (same IR and Raman frequency), C5/C7 odd rings $\sim 1520 / 1550 \mathrm{~cm}^{-1}$ [224] (Table 1). For this achievement some revised aspects of the carbon Raman spectroscopy fundamentals are suggested to bring clarification and we recall next. 


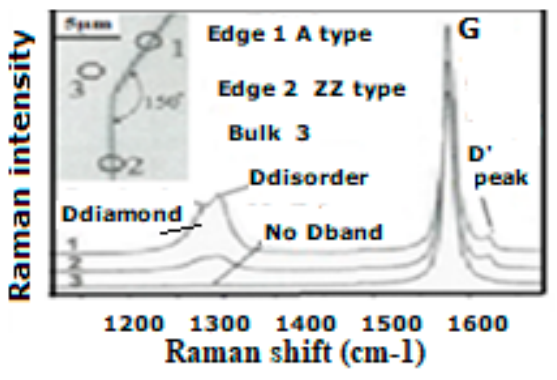

(a)

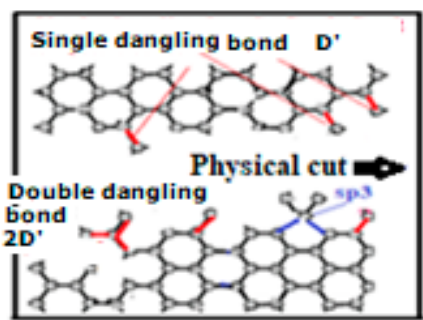

(b)

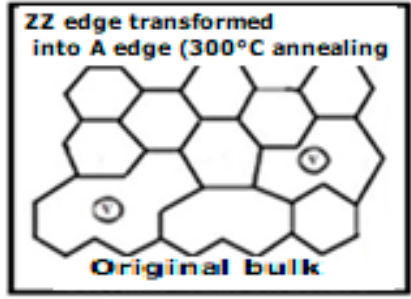

(c)

Figure 12. Graphene edge analysis of cut graphene plane and scheme of edge modification. (a) Raman spectra of cut graphene by Cançado et al. [222] by permission of the Physics Review Letters. D $\left(1333 \mathrm{~cm}^{-1}\right)$, D disorder peaks: GeA $\left(\sim 1350 \mathrm{~cm}^{-1}\right)$ and $\mathrm{D}^{\prime}$ disorder Csp2-Csp2 $\left(\sim 1620 \mathrm{~cm}^{-1}\right)$ are shown. Sharp G peak means that no disorder exists on hexagonal sp2 rings. (b) Our proposed scheme of graphene cut edge with the formation of sp3, single and double dangling Csp2-Csp2 corresponding to $\mathrm{D}$ diam, $\mathrm{D}^{\prime}$ and 2D' peaks. (c) Our proposed scheme of voids formation associated to the thermally induced $\mathrm{ZZ}$ edge transformation into the A edge with internal $\mathrm{ZZ}$ and A edges on formed voids.

\subsection{Refined Carbon Raman Spectroscopy}

The classical Raman theory [225] has been refined with quantum mechanical aspects involving phonon modes distribution (Figure 13) and photon/electron/phonon scattering represented in the reciprocal space $[150,151,226,227]$. The Raman frequency corresponding to the homogeneous and ordered bulk structure could be satisfactorily calculated for diamond [189,190] and graphene [150,151]. However, this is not the case for the so-called "Ddisorder" peak as shown precedingly. It must be emphasized that among the different conditions which must be fulfilled, a Raman effect can only exist when the momentum and energy conservation laws are fulfilled [228]. The so-called "Ddisorder" peak was assigned to phonon backscattering on defects with the double resonance Raman effect. It is represented in the reciprocal space with the so-called "extra-valley" transitions between the Brilloin zones $[150,151,170,226]$.

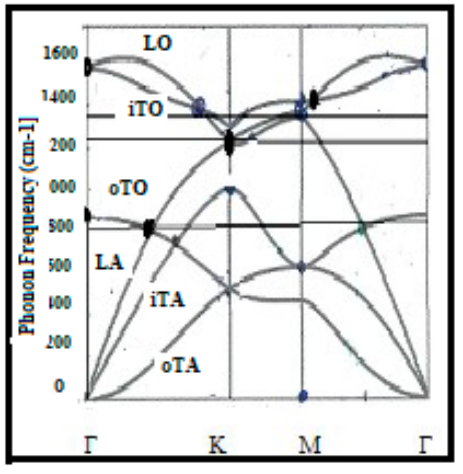

(a)

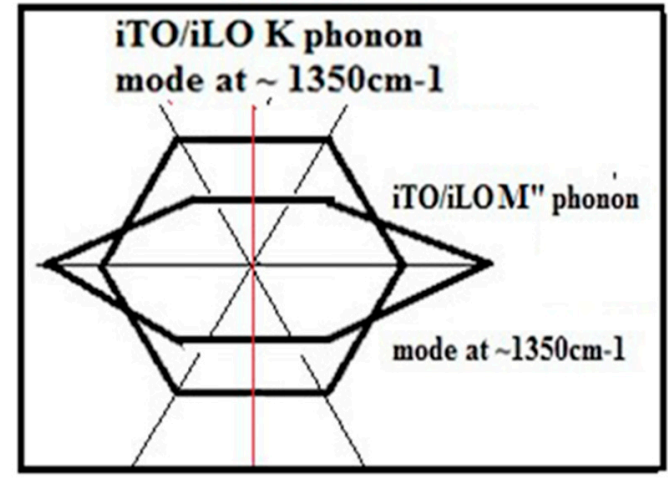

(b)

Figure 13. Phonon dispersion curves in graphene by Lazzari et al. [227] with permission of Physical Review B. (a) At $1350 \mathrm{~cm}^{-1}$ (the frequency of so-called Raman D "disorder" peak) two coupled phonon vibration modes corresponding to $\mathrm{K}$ and $\mathrm{M}$ modes and only the $\mathrm{K}$ mode is Raman active. (b) Representation of $\mathrm{K}$ and $\mathrm{M}$ coupled vibration mode for a hexagonal sp2 ring with perpendicular wave vectors. $K$ mode corresponds to the vibration of A edge meanwhile the $\mathrm{M}$ mode is the vibration mode of the ZZ edge. iTO in-plane transverse optical mode, oTO out of plane transverse optical mode, LO Longitudinal optical mode, LA longitudinal acoustical mode, iTA in-plane acoustical mode, oTO out of plane acoustical mode 
Table 1. Raman nomenclature for carbon material characterizing.

\begin{tabular}{|c|c|c|c|}
\hline $\begin{array}{l}\operatorname{Raman}\left(\mathrm{cm}^{-1}\right) \\
\text { (Nominal) }\end{array}$ & Peak/Band & $\begin{array}{c}\text { Type of Structure } \\
\text { (Non-Stressed Structure) }\end{array}$ & Type of Bonds Energy in eV \\
\hline$\sim 1330$ & D peak & Ordered Diamond cubic & Csp3-Csp3 7.02 \\
\hline$\sim 1325$ & DH6 peak & Ordered hexagonal diamond & $\sim 7.015 \mathrm{eV}$ \\
\hline$\sim 1200 / 1400$ & Dd band & Amorphous diamond, ta-C & Overlapping with DD band \\
\hline$\sim 1150$ & DD & Edges of Diamond crystallites. & Aliphatic Csp3-Csp3 \\
\hline$\sim 1470$ & DG & Diamond and sp2 edges & Aliphatic Csp3-Csp2 \\
\hline$\sim 1580$ & G peak & $\begin{array}{l}\text { In plane double degenerated } \\
\Gamma \text { phonon mode stationary } \\
\text { vibration of } \mathrm{sp} 2 \text { cyclic ring }\end{array}$ & $\begin{array}{c}\text { Csp2-Csp2 } 7.03 \mathrm{eV} \\
\text { collective bond vibration }\end{array}$ \\
\hline$\sim 1560 / 1620$ & G band & Atomic disorder broadening & Superposition GG, DG, GC5/C7 \\
\hline & GG & $\begin{array}{l}\text { Csp2-Csp2 clusters edge } \\
\text { in a-C and DLC }\end{array}$ & \multirow{2}{*}{$\begin{array}{l}\text { Csp2-Csp2 } \sim 7.03 \mathrm{eV} \\
\text { collective bond vibration }\end{array}$} \\
\hline$\sim 1510$ & GD & Csp3-Csp2 cluster & \\
\hline$\sim 1490$ & $\mathrm{G}_{\mathrm{C} 5}$ & C5 ring & \multirow{2}{*}{$\begin{array}{l}\text { Fullerene C5 }\left(\sim 1550 \mathrm{~cm}^{-1}\right) \\
\text { (upshift by plane curvature) }\end{array}$} \\
\hline$\sim 1540$ & $\mathrm{G}_{\mathrm{C} 7}$ & C7 ring & \\
\hline$\sim 1350$ & $\mathrm{GeA}$ & A edge $0^{\circ} \mathrm{CDR}$ scattering & \multirow{4}{*}{$\begin{array}{l}\text { Free edges: not active with }{ }^{\perp} \\
\text { vertical polarized laser light } \\
\text { Bonded edges: all laser light } \\
\text { polarization }\end{array}$} \\
\hline & & Voids internal A edges & \\
\hline & & 1 st, $2 \mathrm{~d}$ order disorder on edge & \\
\hline$\sim 1300 / 1400$ & GeA band & Broadening by edge disorder & \\
\hline \multirow{2}{*}{$\sim 2690$} & \multirow{2}{*}{$\mathrm{G}_{2 \mathrm{P}}$} & 2 phonon CDR scattering & In plane $2 \mathrm{~K}$ and $2 \mathrm{M}$ \\
\hline & & Any polarized laser light & Preferential in-plane polarization \\
\hline$\sim 150$ & RBM & $\begin{array}{l}\text { Breathing mode of CNT } \\
\text { (radius dependent) }\end{array}$ & Collective phasic stretching \\
\hline$\sim 1600$ & G+ & CNT in plane Longitudinal & Distorted Csp2-Csp2 by \\
\hline$\sim 1560$ & G- & CNT in plane Transversal & $\mathrm{sp} 2$ plane curvature of $\mathrm{CNT}$ \\
\hline
\end{tabular}

However, the usual quantum mechanical Raman theory [150] presents some flaws [229] in agreement with the point that the quantum mechanical theory generally neglects the locality of energy states and that the law of energy conservation is not always respected $[26,98]$. We state that the description of the double resonance back scattering on defects and edges and which is supposed to give account for the so-called "Ddisorder" peak $\left(\right.$ at $\left.~ 1350 \mathrm{~cm}^{-1}\right)$ does not fulfill the energy conservation law [26] (only the momentum conservation). Further on, the usual quantum mechanical description of the Raman effect is not considering the locality of the involved phonons. Therefore, the interference of the phonon being backscattered on a defect with the incident one (resulting into a stationary vibration modes) and the eventual coupling between phonon modes have not been considered either.

Considering that a wave vector in the reciprocal space corresponds to a wave propagation direction in the real space, we could refine this graphene Raman model with interferences of involved phonon modes and in taking into account the coupling between activated electrons and corresponding holes (the so-called Kohn effect) [230] and their different decay times in correspondence to each sort of scattering time [26]. The modified double resonance Raman effect corresponding to the backscattered phonon on edges and defects (we call "Coupled Double Resonance" CDR) can only exist when the backscattered phonon has the same direction with the original incident one $\left(0^{\circ}\right.$ angle backscattering). Otherwise, the law of impulse conservation cannot be fulfilled. To be noted, that the erroneously so-called "D disorder" Raman peak $\left(\sim 1350 \mathrm{~cm}^{-1}\right)$ in graphenic structures was also assigned for the breathing mode of a hexagonal sp2 ring [112]. However, this mode will be evidently quenched with higher number of adjacent rings [25].

Considering that this CDR Raman peak $\left(\sim 1350 \mathrm{~cm}^{-1}\right)$ corresponds to an A-edge vibration mode as shown with micro-Raman $[154,155]$ (Figure 10) and only to be considered on graphite hexagonal 
cyclic ring edges we have proposed the GeA designation for it (Table 1). It is here to be emphasized that the $\mathrm{K}$ mode vibration mode (of the A edges) is coupled to the $\mathrm{M}$ vibration mode (of $\mathrm{ZZ}$ edges).

The above described CDR model explains why the corresponding Raman effect is only appearing on the symmetric A edge on which a $0^{\circ}$ angle backscattering is possible (Figure 14).

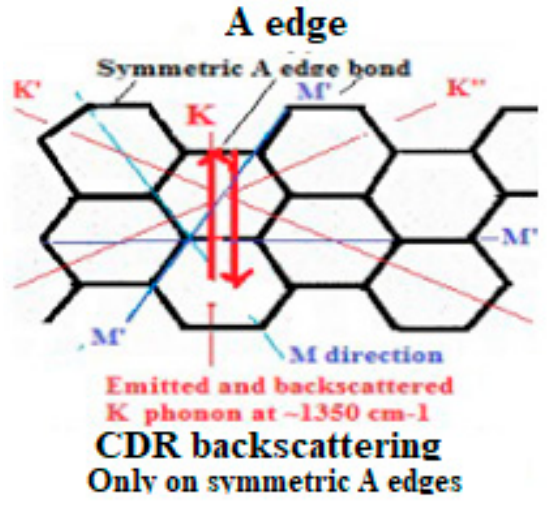

(a)

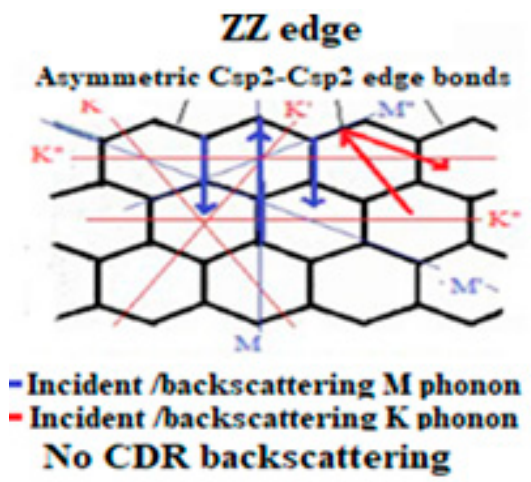

(b)

Figure 14. Phonon backscattering and Raman conditions at $1350 \mathrm{~cm}^{-1}$. (a) CDR Raman scattering conditions are fulfilled on a symmetric A-edge and for which in-plane $\mathrm{K}$ phonon at $\sim 1350 \mathrm{~cm}^{-1}$ is perpendicular to A-edge. No CDR Raman scattering on asymmetric graphene A edge of respective $\mathrm{K}^{\prime}, \mathrm{K}^{\prime \prime}$ orientation. (b) No $0^{\circ}$ angle backscattering on the $\mathrm{ZZ}$ edge for $\mathrm{K}$ and $\mathrm{M}$ phonon at $\sim 1350 \mathrm{~cm}^{-1}$ where edge Csp2-Csp2 bonds are not symmetric to the $\mathrm{K}$ orientation. $\mathrm{M}$ phonon can be split in other phonon of lower energy and therefore, no CDR Raman at $1350 \mathrm{~cm}^{-1}$ can exist on ZZ edge.

This statement appears to be in agreement with the point that no equivalent Raman peak is observed either with non-symmetric A edges of the h-BN structure for instance [26,231]. This model will also explain why this so-called D "disorder" peak is only appearing on the smaller dust polycrystalline graphite particles and not for the defect free polycrystalline graphite bulk. This is suggested to be explained with signal/noise sensitivity and enhanced surface/volume distribution of relevant edge and bulk signals [26,212]. With this revised approach, different kinds of defect in graphenic materials can be characterized more accurately.

\section{Defect Characterizing with Raman Spectroscopy}

\subsection{Phonon K Mode and M Mode Wave Scattering}

From the phonon dispersion curves of graphene [150,151,226,227] (Figure 13) (corresponding also to some extent to sp2 clusters in DLC and to CNT, whenever related larger number of dispersion curves exists here [150], and considering coupled graphene sheet in-plane and out-of-plane vibration modes, it can be deducted that the $G$ peak of graphite and graphenic material is only corresponding to the stationary vibrating mode specific to hexagonal cyclic rings ( $\Gamma$ mode) compatible with the vibration modes of adjacent material structures [26].

In the amorphous graphite (GAC) [208,228], no hexagonal cyclic ring clusters have been formed. Therefore, its broad so-called G band of the GAC material $[208,228]$ cannot include the G peak corresponding to sp2 hexagonal cyclic ring clusters. It is the result of superimposed neighbor Raman peaks being broadened to a band by the atomic disorder.

This is likely the case for C5/C7 bands at $\sim 1500 \mathrm{~cm}^{-1}$ (which is normally at $\sim 1520 / 1530 \mathrm{~cm}^{-1}$ ) and for the adjacent band corresponding to Csp2-Csp2 dangling bonds of sp2 clusters at $\sim 1590 \mathrm{~cm}^{-1}$ (which is normally at $\sim 1620 \mathrm{~cm}^{-1}$ ) [26,223].

On such a Raman band, a stress shifted band corresponding to Csp2-Csp3 dangling bond of a Csp3 cluster is also observed at $\sim 1430 \mathrm{~cm}^{-1}$ (which is normally $1470 \mathrm{~cm}^{-1}$ ). A stress shifted band 
corresponding to a Csp3-Csp2 dangling bond of a Csp2cluster structure which would have been expected at $\sim 1520 \mathrm{~cm}^{-1}$ (which is normally $\sim 1550 \mathrm{~cm}^{-1}$ ) is unlike if no hexagonal cyclic ring can be considered, and when no $G$ peak specific to them is observed.

For the so-called "Ddisorder" Raman peak frequency at $\sim 1350 \mathrm{~cm}^{-1}$ two coupled vibration modes are identified on the phonon dispersion curves (Figure 13). The K mode (transverse to A-edge) and the $\mathrm{M}$ mode (diagonal direction in a hexagonal cyclic ring) (Figure 13b). However, according to theoretic predictions $[150,151]$ only the K mode is subject to some Raman effect and can give account for the "Ddisorder" Raman signal with a double resonance backscattering, meanwhile the M mode will not (Figure 14). This explains why the so-called "Ddisorder" peak is not observed on the ZZ edges in agreement with the preceding discussion [154,155] (Figure 10).

An effect which is also confirmed with the Raman spectroscopy of the h-BN material for which no equivalent peak to the carbon D "disorder" peak exists [231], in contrast to the possible existence of an intense so-called 2D peak (2GeA) which is observed in some graphene Raman spectra which paradoxically are not showing any so-called D disorder peak (GeA) $[218,219]$.

The addition of two $\mathrm{M}$ modes (complementary $\mathrm{M}^{\prime}, \mathrm{M}^{\prime \prime}$ ) can form a new vibration mode with double frequency and the same direction than the $\mathrm{K}$ mode and for which a double resonance $0^{\circ}$ angle backscattering can fulfill the impulse and energy conservation laws (thus, subject to a Raman effect).

The same is to be considered with the addition of two complementary $\mathrm{K}^{\prime}$ and $\mathrm{K}^{\prime \prime}$ modes, which can form a new vibration mode of double frequency with a wave vector perpendicular to an A edge and corresponding to a so-called 2D Raman peak (2GeA).

Therefore, the observed 2D peak can result from the addition of some vibration modes, in which each of them separately considered cannot produce a so-called D disorder Raman peak (A edge K mode). Thus, explaining the possible much higher intensity of the so-called 2D peak compared to the so-called "D disorder" peak [218,219] (Figure 11) and considering that the overtones of the so-called D disorder peak used to be weaker than the basic corresponding vibration mode.

\subsection{Defect Types to Be Considered for NEMS Engineering}

Independent from those associated to doping (such as B and N) and contamination (such as $\mathrm{H}$, $\mathrm{O}$ and $\mathrm{N}$ ) and completing some description of defects in graphenic materials (multilayer stacking anomalies), several sorts of "intrinsic" defects have been identified which can appear in the form of network discontinuities in the graphenic bulk and on their external edges (Figures 12 and 15) and which have significant consequences on NEMS properties [21-23,150,151,169].

- Vacancies and voids with different "internal" edges. Single vacancy has only ZZ edges and can be identified with "2D" (2GeA) Raman peaks when no "Ddisorder" (GeA) peak is observed or when the "2D" peak is more intense than the "D disorder" (GeA) peak [171] (Figure 11).

- Interstitials which can be rearranged during annealing in forming odd ring C5/C7 ring (SW defects) $[151,200]$ with possible additional vacancy formation (Figures 10b and 12c) [26].

- Edge discontinuities resulting for instance from graphene plane cut [222] can produce on the cutting edge single and double aliphatic Csp2-Csp2 edge dangling bonds at $\sim 1620 \mathrm{~cm}^{-1}$ and $3240 \mathrm{~cm}^{-1}$ ) and which are corresponding to so-called D'disorder peak (Figure 12a). Those can evidently modify chemical reactions and material rearrangement on graphenic external edges.

- Graphene rippling has a focused high interest strongly affecting their mechanical and optoelectronic properties and their electric and heat conduction [232-234].

On a single vacancy of graphenic material, no internal A edge is formed and only internal ZZ edges exist. This suggests that the single vacancy will not produce any GeA Raman peak, contrary to larger voids which have both internal A and ZZ edges. In order to reduce the confusion between the $\mathrm{D}$ diamond and so-called "D disorder" peaks and very high impact on carbon-based MEMS and NEMS quality and performances (opto-electronical, electric and thermal conductivity properties and density of cohesion energy), we have suggested to modify the designation nomenclature with Table 1 [26]. 


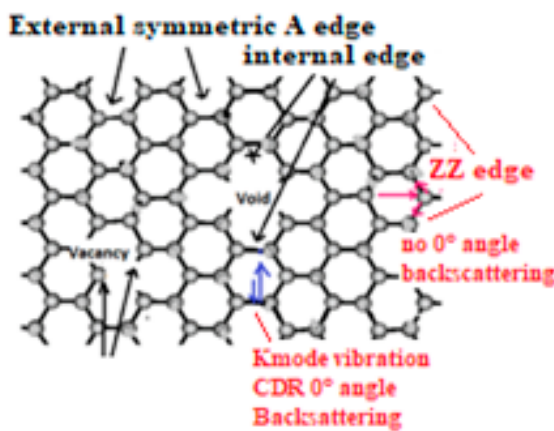

(a)

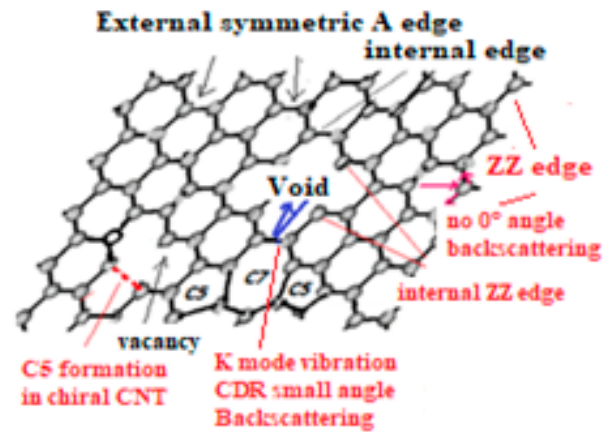

(b)

Figure 15. Defect in graphene bulk (vacancies and voids). (a) Phonon backscattering on external and internal A edges and ZZ edges in a metallic graphene. No Raman double resonance is possible on the internal edges of vacancies ( $\mathrm{ZZ}$ edges) in contrast to voids where symmetric A edges exist. (b) Formation of $\mathrm{C} 5 / \mathrm{C} 7$ odd rings and some internal A edges on vacancies of chiral graphene in consequence of chiral distortion. The reduced A edge asymmetry allows local Raman double resonance (in consequence of Heisenberg incertitude criteria).

Considering edge dangling electrons, easy chemical reactions with recombination energy release can be considered. Atomic and molecular species can be chemisorbed on vacancies (via their internal edges) and with which some new electronic band configuration can be obtained and which can determine some specific graphene functionalizing [10,11,21-23].

However, those can also produce sp3 atomic rearrangement in the surroundings of the vacancy/void if the released energy is able to produce sufficient electron activation. In such a case a dielectric material can be formed which will strongly affect the originally expected high electric conductivity.

\subsection{Local Atomic H6 Diamond Rearrangement}

In addition to thermal transformation of the $\mathrm{ZZ}$ edge into more stable A edge [155] with the formation of additional vacancies (Figure 12c) [26], local diamond atomic rearrangement of graphenic materials can be produced with quantum electronic activation of higher energy, and with which graphene can be locally transformed into a dielectric H6 diamond structure [233] (Non shifted Raman peak at nominal $\sim 1325 \mathrm{~cm}^{-1}$ ) corresponding to a buckled hexagonal structure containing only sp3 (Figure 3).

We suggest these being at the origin of the graphene rippling and which is much affecting the electric conductivity of graphene [234] and the mechanical properties of graphenic material. This is suggested to explain the higher stiffness of nano poly-crystal diamond, where the crystallite boundary material is containing graphenic materials which have been partially transformed in sp3 substructures and the whole diamond material is interlinked by more isotropic diamond material [235].

Refined lecture of produced Raman spectra is clearly showing that an $\mathrm{H} 6$ diamond structure has been formed $\left(\sim 1328 \mathrm{~cm}^{-1}\right.$ ), meanwhile the $\mathrm{G}$ peak appears at $\sim 1580 \mathrm{~cm}^{-1}$ (no longer compressive stress). Considering the reduction of graphene oxide, a process during which some $\mathrm{O}-\mathrm{X}$ molecules are formed with corresponding higher energy release $(X=H, O$, etc. $)$ [236] are able to produce some diamond like quantum electronic activation (Figure 16). This is also well shown with other experiments especially after oxygen etching of multilayer graphene [205] (Figure 17) and [237] (Figure 18) and with the modification of the sp2/sp3 content which can be evaluated from the plasmon spectra, and more easily with the sp2 and sp3 carbon AUGER peaks of XPS spectra [25]. 


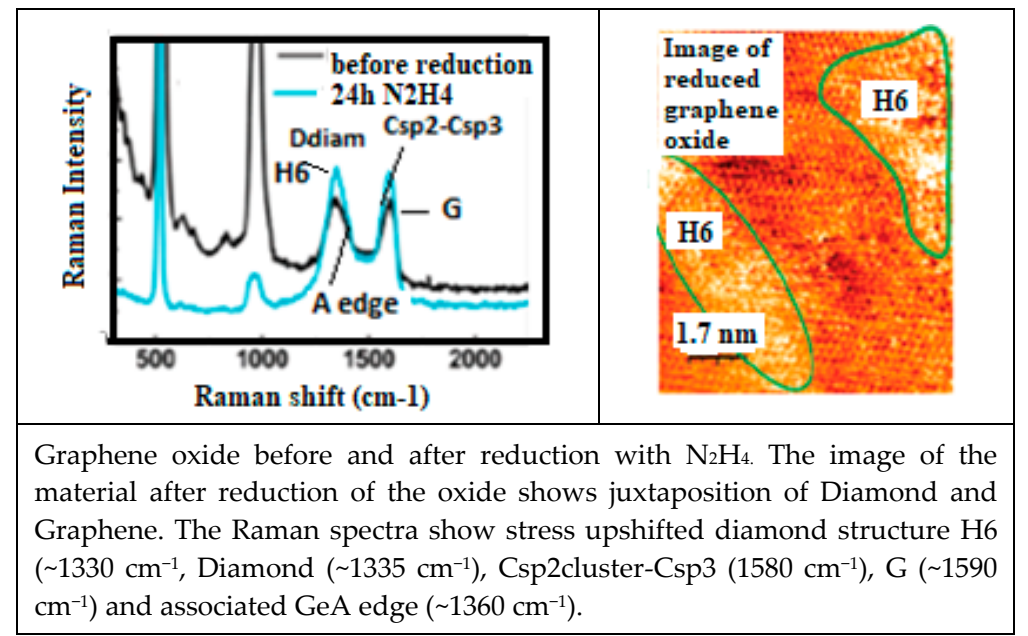

Figure 16. Graphene rippling and local H6 structure formation. Note: Reduced GeA edge after reduction and increase of $\mathrm{H} 6$ diamond by C. Gómez-Navarro et al. [236] with permission of the New Journal of Physics.

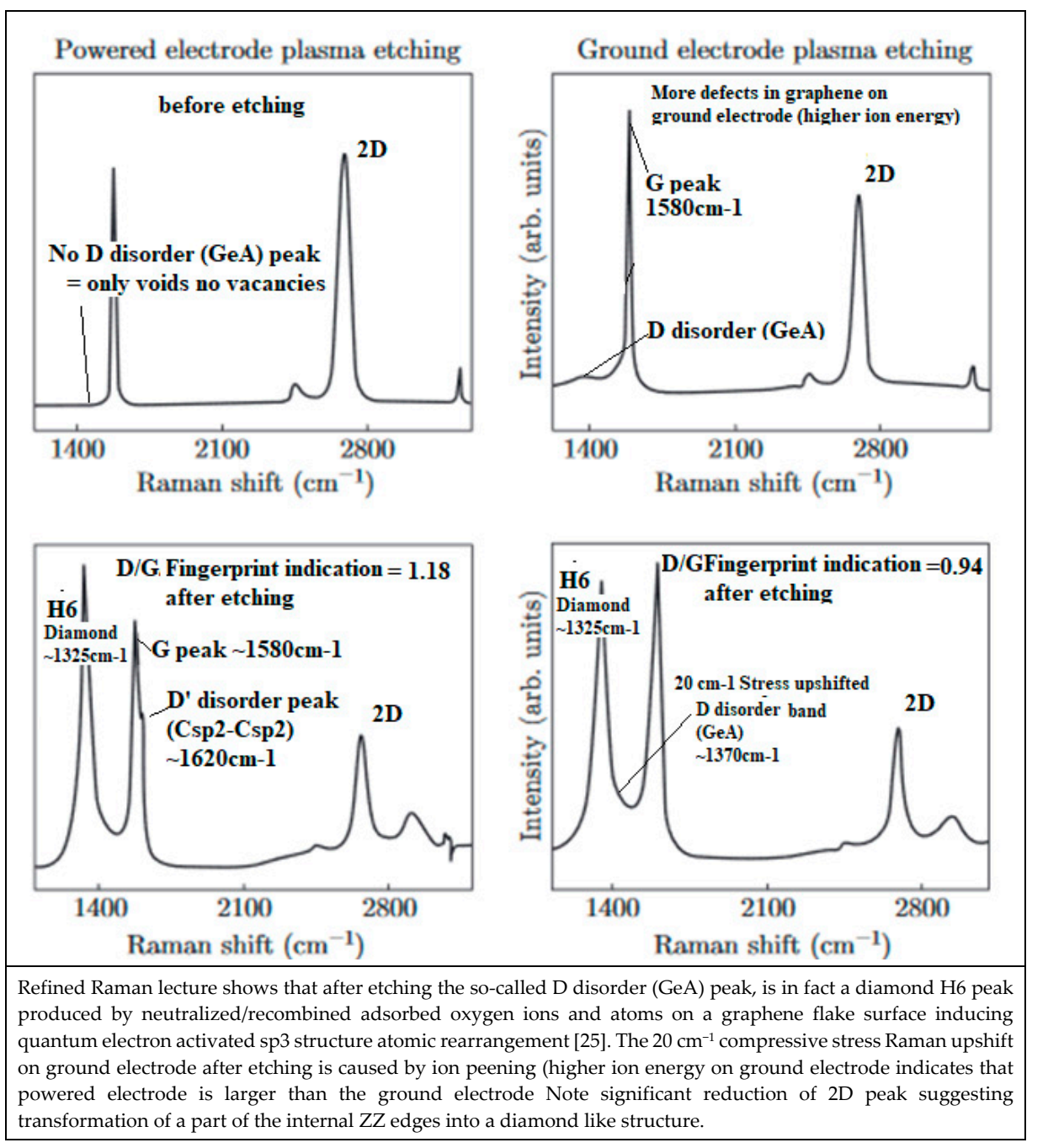

Figure 17. Raman spectroscopic results of oxygen plasma etched graphene by Al-Mumen et al. [205] with permission of Nano-Micro Lett. 


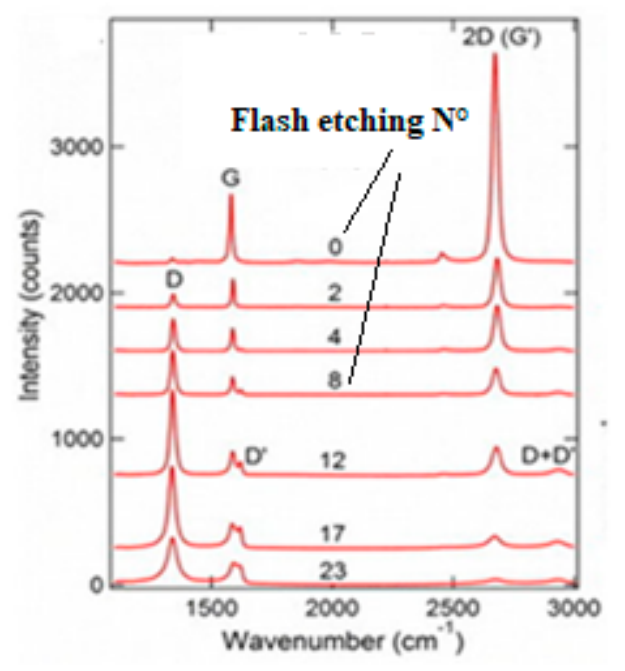

After 12 plasma flashes, a compressive stress upshift appears on the $G$ peak which intensity is strongly reduced suggesting the transformation of the graphene into a diamond material. The so-called $\mathrm{D}$ peak is mainly an upshifted H6 diamond peak, beside a weak GeA band and a much reduced 2D (void defect) peak. The $\mathrm{D}^{\prime}$ peak (dangling Csp2-Csp2) indicates that internal edges of voids are destroyed

Figure 18. Example of revised interpretation of Raman spectra of oxygen plasma etched graphene by Childres et al. [237] with permission of the New Journal of Physics.

In addition to defects which can affect the properties of graphenic material, the selective CNT adsorbtion efficiency (depending on adsorbtion energy) for molecular compounds of different shape must be considered, and which also depends on the CNT chirality and which are influencing the optoelectronic and mechanical properties and the volume and density of the formed CNT/adsorbate system. Recent high interest has been focused on the way to select the different types of SWCNT [238]. They can be separated with some selective buoyancy effects described elsewhere [239] and which appears of great importance for CNT based synthesis of complex helicoidal structures $[11,81,82]$. It is suggested to be at the origin of Precambrian abiotic synthesis of early NRA life molecules [240].

\section{Application Developments}

\subsection{Role of Interface Structure on Composite Material Properties}

\subsubsection{Anchoring and Adhesion of Graphenic Materials with Counter-Facing Materials}

Graphenic materials have been first used for more performing load-bearing applications $[64,65,241]$. CNT powders are mixed with metal alloys, polymers or precursor resins to increase stiffness, strength and toughness and also heat and electric conducting properties. For instance, bulk graphene (reduced graphene oxide)-reinforced $\mathrm{Al}$ matrix composites with significantly improved mechanical properties in comparison to $\mathrm{Al}$ based alloys, and which is reducing cost, brittleness and cracks formation [242]. MWNT-polymer composites reach conductivities as high as $10,000 \mathrm{~s} \mathrm{~m}^{-1}$ at $10 \mathrm{wt} \%$ loading and is used for electrostatic assisted painting and which is thought to be used for anti-icing (with heat generated by electric resistivity) and microwave absorption $[243,244]$.

However, these enhancements depend on nano particle size and shape, aspect ratio, alignment, dispersion and interfacial interaction. The last aspect will strongly depend on which type of chemical bonds can be formed on the internal edges of vacancies and void and on external edges of graphenic 
particles considering the discontinuities of the added graphenic material and on their number, size and density/unit area of vacancies and voids [200] and which need to be fully characterized.

\subsubsection{Modification of Intrinsic Mechanical, Electric and Optoelectronic Properties}

Graphenic particle properties can be functionalized for specific and improved characteristics corresponding to more or less combined intrinsic mechanical, electric, optoelectrical bulk and surface adsorbtion properties and reactivity. This is to be achieved upon which kind of doping and which sorts of adjacent materials is in contact with the graphenic particle and which can affect the energy distribution of their optoelectronic band structure [101,102,144,158,162,195].

For instance, a graphene coating makes carbon aerogel composite particular elastic and resistant to fatigue [245]. Mechanical properties of high-aspect-ratio CNT can be tailored upon added silicon carbide coating [246], better performing transparent conducting electrodes can be achieved with transparent CNT sheet [243,244] and in using graphene silica composite [247]. Electric conductance could be strongly increased with added iodine and especially with copper doping [162-164]. Noteworthy the achievement of very high frequency nano transistors in making use of very low resistivity and ballistic electron transport condition in graphene sheets $[167,168]$. This, in analogy to superconductivity and which can be comprehensively described with a new model which consider the synchronic electron-phonon gating effect and the reduced fermi surface atomic rugosity and the reduced amplitude of transverse phonon in a graphene plane [29].

Transparent electric conducting mechanical and chemical resistant epoxy could be produced with magnetic molecule functionalized CNT [165]. More performing anode [166] and optimization of MWCNT/LIFePO4 cathodes have been achieved for Li-Ion battery [248]. Those are expected to be further improved with better compromise between electron conductivity and proton diffusion barrier properties [28]. 3D macroscopic carbon material scaffold with combined electro-mechanical properties could be developed [249]. Making use of combined piezo-electric properties, electro-mechanical resonator [249] and improved micro-loudspeaker could be produced [250,251]. Arrays of vertically aligned helicoidal CNT could be produced for better mechanical deformation for high frequency electric contact [252], Superelastic CNT aerogel muscles for bio-application [253].

However, these enhanced properties are strongly dependent on defect type, size and number and which must be characterized in order to be able to achieve some desired compromise between higher solid-state properties and precedingly described anchoring effect which is influencing the adhesion, the mechanical and chemical stability and other interfacial electronic effects. Notwithstanding, that eventual phase transition must be comprehensively kept under control.

\subsubsection{Local Activation of Phase Transitions on Edges and in Graphene Bulk}

Incidence of high energy activation on phase transformation from graphenic material towards diamond material, could be many times unconsciously demonstrated for long. This can be stated in considering several corresponding Raman spectra features:

(a) With the differentiation between so-called "Ddisorder" peaks (GeA) and the neighbor collective vibration modes of the $\mathrm{D}$ diamond peaks and band $\left(\sim 1330 \mathrm{~cm}^{-1}\right)$

(b) The related Csp3cluster-Csp2 $\left(\sim 1470 \mathrm{~cm}^{-1}\right)$ and Csp3cluster-Csp3 structure $\left(\sim 1150 \mathrm{~cm}^{-1}\right)$.

(c) In considering some possible stress up- and down-shift which can be checked on the G peak.

(d) The differentiated analysis of the so-called G band which is not always containing a nominal G peak (corresponding to ordered graphitic and graphenic Csp2 material at $\sim 1580 \mathrm{~cm}^{-1}$ when not stress shifted and which can be eventually broadened by disorder). They can correspond to the superimposition of neighbor shifted other peaks and bands [26,180-182,208,209].

Attention must be brought to the point that modification of mechanical properties of crumpled graphene sheet (graphene rippling) is not only the consequence of the new geometric non-flat surface shape $[232,233]$, but almost basing on a phase transformation from a graphenic state toward dielectric 
H6 and diamond state (as we observe on corresponding Raman spectra). This phase transformation can be activated by various means (UV, external polarization, chemical recombination and ion and electron electric neutralization energy release) $[25,234,235]$. However, this eventual phase transformation will not be always homogeneously distributed, as observed for instance with the reduction of graphene oxide by Gomez et al. [236]. This explains the observed increased ohmic resistance (by mix of juxtaposed dielectric and highly conducting materials). In addition, some associated material shrinking is to be considered, which can cause cracks and increased brittleness and reduction of heat transfer capacity.

\subsection{Friction and Wear}

Some NEMS system includes rotating parts for which reduced wear rates and friction can achieve longer life time and higher number of mechanical cycles [254]. Mechanical robustness of a polymer substrate can be increased with an adherent graphene coating [255]. Considering the reduced chemical reactivity of defect free graphene surface, stronger adhesion of graphene on a polymer substrate (or reverse situation) is only possible with the formation of chemical stronger interfacing bonds on graphene vacancies/voids internal edge. However, on these spots, we suggest that released energy from chemical recombination of $\mathrm{H}_{2}, \mathrm{C}-\mathrm{C}$ and new formed chemical bonds on the internal void edges can also transform the graphene material in the vicinity of these spots into a more wear resistant tribological diamond like material (which can be evidenced with corresponding Raman Ddiamond peak/band different from the so-called "Ddisorder" peak (GeA edge coupled double resonance vibration mode) [256].

These combined effects are suggested to explain why non-expected particularly strong reduction of wear and friction have been obtained on graphene coated metallic substrates sliding in dry nitrogen after the graphene coating begin to be corrugated with accumulation of sliding graphenic wear residues containing dissociated nitrogen [257]. This is to be considered with the very high $\mathrm{N}_{2}$ chemical recombination energy release, which can enhance the diamond like atomic rearrangement process [26]. To be observed that epitaxial graphene grown on $\mathrm{SiC}$, can also be transformed into an epitaxial diamond structure. However, because of the much smaller interatomic distance in graphene than in $\mathrm{SiC}$, interfacial atomic mesh mismatch and induced tensile stress is expected to form many more vacancies and voids. Thus, creating new additional stronger $C-C$ interface edge bonds $(\sim 7 \mathrm{eV})$ which can enhance precedingly described effect [258].

\subsection{Yarn and Scaffolds}

High performing fibers and scaffold could be manufactured with the spinning of longer CNT and wires in considering pressure induced interlinking of adjacent CNT [259-262]. Enhanced fiber strength is obtained when fiber manufacturing is associated to polymer between the tubes which can better interlink the CNT via void defect anchoring effects $[263,264]$ and also in causing diamond like atomic rearrangement in the vicinity of the voids (considering that simple vacancies will not be large enough for receiving all reactants necessary to such atomic rearrangement and with which stronger interlinking can be produced). However, such a process involving some phase transformation from graphene to diamond $\mathrm{H} 6$ phase may reduce its electric conductivity.

We suggest that the higher electric conductivity of $\mathrm{Cu}$ doped metallic CNT [265] is obtained when vacancies and voids can be filled with some atomic species able to form an electric conducting continuous flat CNT surface (similar to superconductivity conditions, as previously discussed).

For such application semiconducting CNT must be avoided, correct orientation of metallic CNT particles must be secured. Diamond-like atomic rearrangement forming more dielectric material must be avoided (or reduced to thin interlayer material, through which the electric conductivity is obtained by electron tunneling, all the more that diamond and ta-C materials have low work function). Addition of copper can fill larger voids with reduced chemical recombination energy release (Cu-C binding energy is very low) and with electron enrichment of the electron conduction band edges and in agreement with achieved high electric conducting CNT/Cu composite materials [163,164]. It will be 
essential here to optimize size, density and number of voids in the precursor graphene material and its contamination being reduced, considering that atomic rearrangement towards more dielectric materials has to be minimized. Using biochar material, a graphitic electric conducting carbon dust [266], its 3D isotropic distributed orientation is contributing to easier reproducibility of carbon-based composited materials [267].

\subsection{Micro and Nano Interconnecting and Thermal Management}

With the possibility of increased strength, elasticity, heat and electric conductivity and reduced copper electromigration, low weight and low cost, carbon-based fibers appear to be interesting materials for micro and nano interconnection and thermal management of many electromechanical and electronic devices [268-274]. With bottom up technology vertical tubes and fibers can be catalytical nucleated with strong bonds on its specific substrate alloy materials [275]. However, great care must be brought to the achievable low ohmic, strong and stable electric contact to other added parts of the NEMS. Any possibility to have the contact wire/fiber material being transformed into a low graded electric conducting material must be avoided. It must be controlled and managed (a) the diamond atomic rearrangement forming dielectric material by higher chemical recombination energy release (CRER) and (b) the surface passivation with reactive contaminants which can affect both the adhesion and the mechanical strength of the link and the resistivity of the electric contact. Cleanliness and selection of fiber type on defect content, composition, mechanical and electric properties will be a major concern.

\subsection{Electronical and Optoelectronic Functions and Field Emission Effects}

Different nano electronic devices combine [134] chemically and electric field modifiable semiconducting properties, low work function and different mechanical properties, which can be associated to high thermal conductivity, high current density and very high mobility, and ballistic properties, low voltage field emission properties and fast switching.

This could be achieved and/or improved with associated efficient chips cooling being up to ten times better than with copper and with which electromigration of copper can be avoided [274], especially in making use of polymer/graphene and CNT composites nano thin films [243-246] and with which different devices could be elaborated. Among them, flexible electronic integrated circuits and transparent thin film could be produced on transparent polymer and glass substrates, thin film transistors (TFT) and Field effect transistors (FET) [166-168,276-281]. Those are thought to be used for low power/low energy consumption field emission display $[140,141]$ with which organic light emitting diode (OLED) can be activated [142] or selective light emission can be produced on optoelectronic functionalized CNT field emitters [142,143]. Here, particular care has to be brought to reduced contamination and defect contents and to possible phase transitions especially induced by various chemical recombination energy release activation.

\subsection{Solar Cells, Hydrogen and Energy Storage and Energy Conversion}

\subsubsection{Solar Cells and Energy Storage}

Organic solar cells have focused much interest, since low cost flexible thin film photovoltaic system could be produced with them [282-284]. Graphene polymer composite could increase the conversion efficiency, in reducing electron/hole recombination, since electrons in the conduction band can be faster evacuated $[285,286]$. Such graphene polymer composite exhibit also transparent conductive properties which are thought to be used for displays and for solar cells, considering they are much cheaper than usual ITO (Indium Tin Oxide) and related TCO (Transparent Conductive Oxide) [243,244,247,282-284]. As a result of their extreme high electric conductivity, they can be used as transparent electrodes in very low film thickness. They can be deposited with spin deposition techniques without vacuum technologies. However, polymers are not best diffusion barrier and give little protection against humidity and low weight elements, and that thicker coatings can absorb a 
significant part of the solar light. Therefore, it will be useful to protect them with less permeating transparent ta-C encapsulating which can provide additional anti scratch resistance and resistance against hard UV [121] (Figure 19). Harder stress annealed transparent ta-C exhibiting very high antireflection in addition to other interesting properties, can generally enhance over the double of yearly solar light harvesting per unit surface, in collecting solar light with oblique incidence and especially azimuthal light during many days along the year where the sky presents some luminous coverage [287].

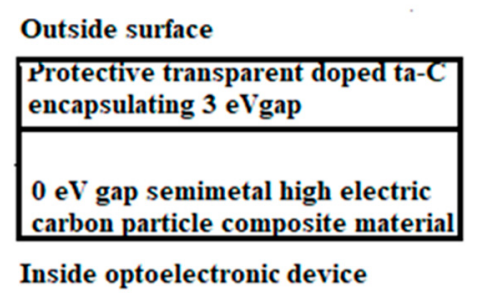

Figure 19. Scheme of conducting system with little conducting doped ta-C coating on highly electric conducting composite graphene.

Association of different carbon-based materials have been considered for improved electric energy storage and energy conversion (fuel cells) [28,288-290]. Several major aspects suggested to be considered are the extreme differences in work function (from lower than $1 \mathrm{eV}$ up to over $5 \mathrm{eV}$ ) between different categories of carbon materials and other properties which must be correctly distinguished. On a low work function graphene surface, $\mathrm{H}+$ can be neutralized and recombined to $\mathrm{H}_{2}$ and induce phase transformation into more diamond like materials. Meanwhile, on a doped ta-C surface (highly diamond like) no chemo-structural change can be expected with such $\mathrm{H}_{2}$ recombination energy release (CRER) activation mechanism.

Thorough distinction between different types of carbon materials must be achieved, considering their different porosity and surface rugosity, chemical inertness, electric conductivity, work function and diffusion barrier properties (for instance homogeneous, harder, dense packed ta-C have best diffusion barrier properties including for $\mathrm{H}^{+}$protons which other carbon materials will not have) [28]. Despite their poor electric conducting properties (whenever being doped), electric transport can be maintained through very thin ta-C layers by electron tunneling effect and can be used in multilayer nano materials with which low friction and high antiwear properties can be associated to sufficient electric conductivity for sliding contact brushes for instance [256].

\subsubsection{Hydrogen Storage and Photocatalytic Production from Water}

Considering hydrogen in modern clean energy management, much interest has been developed for its storage efficiency and low-cost production [291]. Hydrogen can be stored at ambient temperature with much less energy than necessary for cooling and gas compression in making use of temperature dependent and reversible adsorbtion capability on CNT external and internal wall surface [292,293]. Physical adsorbtion of $\mathrm{H}_{2}$ on CNT is to be considered on its defects where dangling bond electron stay captive, meanwhile chemisorption corresponding to the formation of $\mathrm{C}-\mathrm{H}$ bonds on the graphene surface and on its vacancies and voids internal edges $(\sim 4 \mathrm{eV})$ appears to be unlike, because the $\mathrm{C}-\mathrm{H}$ bond energy is lower than the $\mathrm{H}-\mathrm{H}$ bond $(\sim 5 \mathrm{eV})$ of a $\mathrm{H}_{2}$ molecule. Therefore, hydrogen storage on graphenic material will be much dependent from contaminants which can screen the defects [294]. With the dissociation of adsorbed $\mathrm{H}_{2}$ by catalytic and electrolytic effects [295], $\mathrm{H}$ atoms can be better chemically bonded to the graphene substrate defect edges. Consecutive temperature activated $\mathrm{H}_{2}$ recombination can release the stored atomic hydrogen in form of molecular $\mathrm{H}_{2}$. The desorbtion mechanisms is generally endothermic and is absorbing energy, meanwhile the $\mathrm{H}_{2}$ recombination and process is releasing energy with which the CNT material can be locally converted into some 
denser H6 diamond like material and will enhance the formation of defect with tensile stress. Process optimization will depend on defect characteristics.

Hydrogen production with photocatalytic dissociation of water has been thought in using the $\mathrm{CNx}$ material which can be tailored on its optimized optoelectronic gap ( 1.8 eV) and with sufficient electric conductivity and with which solar light can dissociate water molecules with $\mathrm{H}_{2}$ formation $[203,296]$. Enhanced efficiency of similar process has been obtained with association of usual catalytic materials such as palladium $/ \mathrm{TiO}_{2}$ material [295]. However, these materials can be degraded by oxidative processes which will harm to their operational life time. We suggest that chemically more stable doped ta-C which can also be tailored at $1.8 \mathrm{eV}$ gap and presenting some anti-soiling properties might give the route for better satisfactory solutions.

\subsection{Sensors, Medical Applications and Miscellaneous}

Functionalizing of graphenic materials, assembled to yarn could produce electrosensitive elastic fibers thought to be used for artificial muscles [253] and highly performing bio sensors [68]. Several Carbon based NEMS sensor principles can be distinguished: Selective mechanical properties (cantilever and membrane deformation, mass selective resonance) [35-38,69,71], selective molecular adsorbtion of functionalized graphenic materials [297-300] and selective optoelectronic modification [158,159]. A model for biologic and artificial olfaction had been proposed based on the appearance of transient polarization pulse which can be produced by selective adsorbtion on specific molecular compounds wrapping an electric conductor [100]. With the functionalized graphenic material, its optoelectronic band organization is modified and can present IR fluorescence being activated by specific adsorbtion energy release, and an effect which is used for instance for the monitoring of glucose in the blood [159,160].

A reverse effect is to be considered, when some functionalized graphenic material is adsorbed on biologic cells and tissues which can have toxic and antibacterial effects and being used for cancer therapy [101-107]. CNT scaffold composed by strongly interconnected fibers [249,301] can be used for bone tissue engineering [302]. Noteworthy, is the possibility to produce some helicoidal molecular structure with the adsorbtion of proteins [303] with are expected to have specific sensor properties. The same effect is suggested to be at the origin of first terrestrial abiotic RNA synthesis [240]. Many other applications have been developed, using graphenic composite scaffold for water nano-filtering and purification [304], as flame retardant material which combines heat conducting cooling effect with formation of diffusion barrier material [305], plasmon enhanced detection of microwave [306], photodetection with broadband polarimetry, with functionalized CNT upon corresponding photon energies and making use of their electric conductance anisotropy [161].

For all these systems, it appears the decisive role of defects of the graphenic sensor materials on which functionalizing molecules will be anchored with modified optoelectronics. Contaminants can screen and modify the defects and the optoelectronic organization of the functionalized graphenic materials and quantum electronic activation by specific chemical recombination energy release can transform a graphenic/polymeric material into diamond and diamond like dielectric material. The last effect which is thought to be at the origin of manufacturing of high performing diamond/diamond-like composite material for abrasive resistant and more performing cutting tools with 3D printing of liquid polymer/diamond crystallite mixture [307].

\section{Conclusions}

Carbon-based materials have extreme material properties of interest for more advanced NEMS applications. However, despite huge progress particularly with them, their implementation has to face several hindrances $[1,10,23,65]$. Changes to electronic and mechanical attributes of carbon-based materials must fully be explored before their implementation, especially because of high surface area which can easily react with environments. The NEMS design must receive particular attention to contamination and actual material structure and defects which can affect adhesion, surface rugosity 
(rippling corresponding to phase transformation towards H6 diamond and other diamond-like structures), friction (especially on local asperities), electric conductivity, inter connection, optoelectronic properties and surface functionalization. It is necessary to be fully aware about them, and all aspects must be correctly characterized and selected upon their manufacturing processes and their origin in order to be able to optimize and secure achieved results.

For this purpose, revised fundamentals have appeared as essential. This is concerning on one hand the characterizing achieved especially with Raman spectroscopy and on other hand some dramatically neglected effects inducing phase transformation and significant modification of material properties. For instance, with phase transformations of graphene and polymeric material toward diamond and diamond like material by quantum electronic activation and which can be particularly efficiently produced by high energy $\mathrm{H}_{2}, \mathrm{~N}_{2}, \mathrm{O}_{2}$ and $\mathrm{C}-\mathrm{C}$ chemical recombination and electric neutralization energy release and which can produce diamond-like material glassy carbon and/or diamond particle inclusions and different kinds of amorphous diamond materials.

Diamond-like phase transformation appears to be very useful for many anti-wear and tribological application (effects being used for instance by Sandvik for the production of new diamond composite materials [307] or the contrary, when the main advantages of graphenic particles electric and opto-electronical properties have to be preserved and the appearance of defects and cracks by shrinking effects has to be avoided (similar effects exist also with different steel and aluminum based alloy when for instance with recombination of incorporated atomic hydrogen to $\mathrm{H}_{2}$ [207]). For this purpose, the efficient diffusion barrier properties against atomic hydrogen diffusion of very thin harder ta-C coating appear to be of high interest [121]. When being stress annealed without graphitic thermal degradation it is suggested to be used for different kinds of transparent antireflecting, anti-erosion, anticorrosion and anti-soiling encapsulation in association with transparent highly electric conductive polymers for many applications [287].

Funding: This research received neither external nor internal funding.

Conflicts of Interest: I declare that up to my knowledge there is no conflict of interest.

\section{References}

1. Karumuri, S.R.; Srinivas, Y.; Sekhar, J.V.; Sravani, K.G. Review on Break through MEMS Technology. Sch. Res. Libr. Arch. Phys. Res. 2011, 2, 158-165.

2. Mohr, M.; Caron, A.; Herbeck-Engel, P.; Bennewitz, R.; Gluche, P.; Brühne, K.; Fecht, H.J. Young's modulus, fracture strength, and Poisson's ratio of nanocrystalline diamond films. J. Appl. Phys. 2014, 116. [CrossRef]

3. Vetter, J. 60 years of DLC coatings: Historical highlights and technical review of cathodic arc processes to synthesize various DLC types, and their evolution for industrial applications. Surf. Coat. Technol. 2014, 257, 213-240. [CrossRef]

4. Tibrewala, A.; Peiner, E.; Bandorf, R.; Biehl, S.; Lüthje, H. The piezoresistive effect in diamond-like carbon films. J. Micromech. Microeng. 2007, 17, S77-S82. [CrossRef]

5. Lu, J.X.; Cao, Z.; Aslam, D.M.; Sepulveda, N.; Sullivan, J.P. Diamond micro and nano-resonators using laser, capacitive or piezoresistive detection. In Proceedings of the 2008 3rd IEEE International Conference on Nano/Micro Engineered and Molecular Systems, Sanya, China, 6-9 January 2008. [CrossRef]

6. Kauth, C. Electronic Interfaces for Carbon Nanotube Electromechanical Oscillators and Sensors. Ph.D. Thesis, EPFL, Lausanne, Switzerland, 2014.

7. Mashman, M.R.; Ehlert, G.J.; Dickinson, B.T.; Phillips, D.M.; Ray, C.W.; Reich, G.W.; Baur, J.W. Bioinspired Carbon Nanotube Fuzzy Fiber Hair Sensor for Air-Flow Detection. Adv. Mater. 2014, 26, 3230-3234. [CrossRef] [PubMed]

8. Luo, J.K.; Fu, Y.Q.; Le, H.R.A.; Williams, J.; Spearing, S.M.I.; Milne, W. Diamond and diamond-like carbon MEMS. J. Micromech. Microeng. 2007, 17, S147-S163. [CrossRef]

9. Martin-Olmos, C.; Rasool, H.I.; Weiller, B.H.; Gimzewski, J.K. Graphene MEMS: AFM Probe Performance Improvement. ACS Nano 2013, 7, 4164-4170. [CrossRef] 
10. Jiang, S.; Shi, T.; Zhan, X.; Xi, S.; Long, H.; Gong, B.; Li, J.; Cheng, S.; Huang, Y.; Tang, Z. Scalable fabrication of carbon-based MEMS/NEMS and their applications: A review. J. Micromech. Microeng. 2015, 25, 113001. [CrossRef]

11. Katz, E.; Willner, I. Biomolecule-Functionalized Carbon Nanotubes: Applications in Nano-bioelectronics. ChemPhysChem 2004, 5. [CrossRef]

12. Kis, A.; Zettl, A. Nanomechanics of carbon nanotubes. Philos. Trans. R. Soc. A 2008, 366, 1591-1611. [CrossRef]

13. Janas, D.; Koziol, K.K. A review of production methods of carbon nanotube and graphene thin films for electrothermal applications. Nanoscale 2014, 6, 3037. [CrossRef] [PubMed]

14. Zang, X.; Zhou, Q.; Chang, J.; Liu, Y.; Lin, L. Graphene and CNT in MEMS/NEMS applications. Microelectron. Eng. 2015, 132, 192-206. [CrossRef]

15. Sharma, S.; Sharma, A.; Cho, Y.-K.; Madou, M. Increased Graphitization in Electrospun Single Suspended Carbon Nanowires Integrated with Carbon-MEMS and Carbon-NEMS Platforms. ACS Appl. Mater. Interfaces 2012, 4, 34-39. [CrossRef] [PubMed]

16. Varney, M.W.; Aslam, D.M.; Janoudi, A.; Chan, H.Y.; Wang, D.H. Polycrystalline-Diamond MEMS Biosensors Including Neural Microelectrode-Arrays. Biosensors 2011, 1, 118-133. [CrossRef] [PubMed]

17. Choi, J.; Eun, Y.; Pyo, S.; Sim, J.; Kim, J. Vertically aligned carbon nanotube arrays as vertical comb structures for electrostatic torsional actuator. Microelectron. Eng. 2012, 98, 405-408. [CrossRef]

18. Kim, M.-O.; Lee, K.; Na, H.; Kwon, D.-S.; Choi, J.; Lee, J.-I.; Baek, D.-H.; Kim, J. Highly sensitive cantilever type chemo-mechanical hydrogen sensor based on contact resistance of self-adjusted carbon nanotube arrays. Sens. Actuators B Chem. 2014, 197, 414-421. [CrossRef]

19. Choi, J.; Kim, J. Defective carbon nanotube-silicon heterojunctions for photodetector and chemical sensor with improved responses. J. Micromech. Microeng. 2015, 25, 115004. [CrossRef]

20. Schroeder, V.; Savagatrup, S.; He, M.; Lin, S.; Swager, T.M. Carbon Nanotube Chemical Sensors. Chem. Rev. 2019, 119, 599-663. [CrossRef]

21. Lyshevski, S.E. MEMS and NEMS—Systems, Devices, and Structures (2001); CRC Press LLC Corporate Blvd: Boca Raton, FL, USA, 2000; ISBN 0-8493-1262-0.

22. Loh, O.; Wei, X.; Ke, C.; Sullivan, J.; Espinosa, H.D. Robust carbon-nanotube-based nano-electromechanical devices: Understanding and eliminating prevalent failure modes using alternative electrode materials. Small 2011, 7, 79-86. [CrossRef]

23. De Haan, S. NEMS-Emerging products and applications of nano-electro-mechanical systems. Nanotechnol. Percept. 2006, 2, 267-275. [CrossRef]

24. Joshi, R.K.; Kumar, A. Diamond and Related Nanomaterials for MEMS/NEMS Applications. J. Nanomater. 2009, 2009. [CrossRef]

25. Neuville, S. Quantum electronic mechanisms of atomic rearrangements during growth of hard carbon films. Surf. Coat. Technol. 2011, 206, 703-726. [CrossRef]

26. Neuville, S. Refined Raman Spectroscopy Fundamentals for Improved Carbon Material Engineering; Lambert Academic Publishing: Kaiserslautern, Germany, 2014; 169p, ISBN 978-3-659-48909-9.

27. Neuville, S.; Matthews, A. A perspective on the optimization of hard carbon and related coatings for engineering applications. Thin Solid Film 2007, 515, 6619-6655. [CrossRef]

28. Neuville, S. Differentiated Carbon Material for Energy Storage and Conversion. Mater. Day Proc. 2018, 5, 13837-13845. [CrossRef]

29. Neuville, S. Superconductivity described with Electron-Phonon Synchronic Coupling. Mater. Today Proc. 2018, 5, 13827-13836. [CrossRef]

30. Bosseboeuf, A.; Mathias, H. Experimental techniques for damping Characterization of micro and nanostructures. In Advances in Multiphysic Simulation and Experimental Testing of MEMS; Frangi, A., Cercignagni, C., Mukherjee, S., Aluru, N., Eds.; Imperial College Press: London, UK, 2008.

31. Fu, Y.; Du, H.; Huang, W.; Zhang, S.; Hu, M. TiNi-based thin films for MEMS applications. In Advanced Materials for Micro- and Nano-Systems (AMMNS); Singapore-MIT Alliance (SMA): Singapore, 2004.

32. Saito, K.; Iwata, K.; Ishihara, Y.; Sugita, K.; Takato, M.; Uchikoba, F. Miniaturized Rotary Actuators Using Shape Memory Alloy for Insect-Type MEMS Microrobot. Micromachines 2016, 7, 58. [CrossRef] [PubMed]

33. Karpelson, M.; Whitney, J.P.; Wei, G.Y.; Wood, R.J. Design and fabrication of ultralight high-voltage power circuits for flapping-wing robotic insects. In Proceedings of the 2011 Twenty-Sixth Annual IEEE Applied Power Electronics Conference and Exposition (APEC), Fort Worth, TX, USA, 6-11 March 2011. 
34. Zhang, M.; Llaser, N.; Mathias, H.; Dupret, A. High precision measurement of quality factor for MEMS resonators. Procedia Chem. 2009, 1, 827-830. [CrossRef]

35. Rotake, A.D. Heavy Metal Ion Detection in Water using MEMS Based Sensor. Mater. Today Proc. 2018, 5, 1530-1536. [CrossRef]

36. Polster, T.; Hofmann, M. Aluminum Nitride based 3D piezoelectric sensors. Proc. Chem. 2009, 1, $144-147$. [CrossRef]

37. Stampfer, C.; Helbling, T.; Obergfell, D.; Schöberle, B.; Tripp, M.K.; Jungen, A.; Roth, S.; Bright, V.M.; Hierold, C. Fabrication of Single-Walled Carbon-Nanotube-Based Pressure Sensors. Nano Lett. 2006, 6, 233-237. [CrossRef]

38. Stampfer, C.; Jungen, A.; Linderman, R.; Obergfell, D.; Roth, S.; Hierold, C. Nano-Electromechanical Displacement Sensing Based on Single-Walled Carbon Nanotubes. Nano Lett. 2006, 6, 1449-1453. [CrossRef] [PubMed]

39. Lee, J.-I.; Song, Y.; Jung, H.; Choi, J.; Eun, Y.; Kim, J. Deformable Carbon Nanotube-Contact Pads for Inertial Microswitch to Extend Contact Time. IEEE Trans. Ind. Electron. 2012, 59, 4914-4920. [CrossRef]

40. Kaul, A.B.; Wong, E.W.; Epp, L.; Hunt, B.D. Electromechanical Carbon Nanotube Switches for High-Frequency Applications. Nano Lett. 2006, 6, 942-947. [CrossRef] [PubMed]

41. Lee, S.W.; Lee, D.S.; Morjan, R.E.; Jhang, S.H.; Sveningsson, M.; Nerushev, O.A.; Park, Y.W.; Campbell, E.E.B. A Three-Terminal Carbon Nano-relay. Nano-Lett. 2004, 4, 2027-2030. [CrossRef]

42. Jang, J.E.; Cha, S.N.; Choi, Y.; Amaratunga, G.A.J.; Kang, D.J.; Hasko, D.G.; Jung, J.E.; Kim, J.M. Nanoelectromechanical switches with vertically aligned carbon nanotubes. Appl. Phys. Lett. 2005, 87, 163114. [CrossRef]

43. Nguyen, N.T.; Huang, X.Y.; Chuan, T.K. MEMS-micropumps: A review. J. Fluids Eng. 2002, 124, $384-392$. [CrossRef]

44. Roy, S.K. A Survey MEMS Micromotors Assemblies and applications. Int. J. Eng. Res. Gen. Sci. 2015, 3, 2091-2730.

45. Büttgenbach, S. Review Electromagnetic Micromotors-Design, Fabrication and Applications. Micromachines 2014, 5, 929-942. [CrossRef]

46. Hsieh, J.Y.; Kuo, P.H.; Huang, Y.C.; Huang, Y.-J.; Tsai, R.D.; Wang, T.; Chiu, H.W.; Wang, Y.H.; Lu, S.S. A Remotely-Controlled Locomotive IC Driven by Electrolytic Bubbles and Wireless Powering. IEEE Trans. Biomed. Circuits Syst. 2014, 8, 787-798. [CrossRef] [PubMed]

47. Mehta, A.M.; Pister, K. Planar two degree-of-freedom legs for walking microrobots. In Proceedings of the IARP Workshop on Micro \& Nano Robotics, Paris, France, 23-24 October 2006.

48. Kovac, M. Learning from nature how to land aerial robots. Science 2016, 352, 895-896. [CrossRef] [PubMed]

49. Penskiy, I.; Bergbreiter, S. Optimized Electrostatic Inchworm Motors using a Flexible Driving Arm. J. Micromech. Microeng. 2013, 23, 015018. [CrossRef]

50. Chollet, F.; Goedgebuer, J.-P. Improved LiNbO 3 Technology for Reducing Sidelobe Asymmetry in Mode Converter-Based Wavelength Filters. Jpn. J. Appl. Phys. 1998, 37, 979-981. [CrossRef]

51. Liu, A.Q.; Zhang, X.M.; Murukeshan, V.M.; Zhang, Q.X.; Zou, Q.B.; Uppili, S. Optical Switch Using Draw-Bridge Micromirror for Large Array. In Transducers '01 EurosensorsXV, Proceedings of the11th International Conference on Solid-State Sensors and Actuators; Springer: Berlin/Heidelberg, Germany, 2001; pp. 1296-1299.

52. Liu, A.; Zhao, B.; Chollet, F.; Zou, Q.; Asundi, A.; Fujita, H. Micro-opto-mechanical grating switches. Sens. Actuators A Phys. 2000, 86, 127-134. [CrossRef]

53. Ostfeld, A.E.; Gaikwad, A.M.; Khan, Y.; Arias, A.C. High-performance flexible energy storage and harvesting system for wearable electronics. Sci. Rep. 2016, 6. [CrossRef] [PubMed]

54. Arun, A.; Le Poche, H.; Idda, T.; Acquaviva, D.; Badia, M.F.-B.; Pantigny, P.; Salet, P.; Ionescu, A.M. Tunable MEMS capacitors using vertical carbon nanotube arrays grown on metal lines. Nanotechnology 2010, 22, 025203. [CrossRef] [PubMed]

55. Despont, M.; Brugger, J.; Drechsler, U.; Dürig, U.; Häberle, W.; Lutwyche, M.; Rothuizen, H.; Stutz, R.; Widmer, R.; Binnig, G.; et al. VLSI-NEMS chip for parallel AFM data storage. Sens. Actuators A Phys. 2000, 80, 100-107. [CrossRef]

56. Waldner, J.P. Nano-computers and Swarm Intelligence; ISTE John Wiley \&Sons: London, UK, 2008 ; p. 205. ISBN 978-1-84821-009-7. 
57. Shafagh, R.; Vastesson, A.; Guo, W.; van der Wijngaart, W.; Haraldsson, T. E-Beam Nano-structuring and Direct Click Biofunctionalization of Thiol-Ene Resist. ACS Nano. 2018, 12, 9940-9946. [CrossRef]

58. Draz, M.S.; Kochehbyoki, K.M.; Vasan, A.; Battalapalli, D.; Sreeram, A.; Kanakasabapathy, M.K.; Kallakuri, S.; Tsibris, A.; Kuritzkes, D.R.; Shafiee, H. DNA engineered micromotors powered by metal nanoparticles for motion -based cellphone diagnostics. Nat. Commun. 2018, 9. [CrossRef]

59. Godssi, R.; Lin, P. MEMS Materials and Processes Handbook; Springer: Berlin, Germany, 2011; ISBN 978-0-387-47316-1.

60. Zhang, S. Handbook of Nanostructured Thin Films and Coatings: Mechanical Properties; CRC Press Taylor \& Francis Group: Boca Raton, FL, USA, 2010; ISBN 13:978-1-4200-9403-9.

61. Madou, M.J. Fundamentals of Microfabrication and Nanotechnology. In MEMS to Bio-MEMS. Manufacturing Techniques and Applications; CRC Press: Boca Raton, FL, USA, 2011; Volume III, p. 252, ISBN 143-989-5244.

62. Rao, A.V.; Yadav, S.K. An introduction to Nano Electro Mechanical Systems. Int. J. Eng. Sci. (IJES) 2015, 4, 6-9.

63. Ventra, M.D.; Evoy, S.; Heflin, J.R., Jr. Introduction to Nanoscale Science and Technology. In Nanostructure Science and Technology; Springer: Berlin, Germany, 2004; ISBN 978-1-4020-7720-3.

64. Mahakud, R.; Panigrahi, M.; Rath, S. Various Technological Aspects of Nano Electro Mechanical Systems-A Review. Int. J. Anal. Exp. Finite Element Anal. (IJAEFEA) 2014, 1, 1-5.

65. Peng, H.; Li, Q.; Chen, T. (Eds.) Industrial Applications of Carbon Nanotubes; Elsevier: Amsterdam, The Netherlands, 2017; 508p, ISBN 978-0-323-41481-4.

66. Garcia, J.C.; Justo, J.F. Twisted ultrathin silicon nanowires: A possible torsion electromechanical nanodevice. EPL Europhys. Lett. 2014, 108, 36006. [CrossRef]

67. Ke, C.; Espinosa, H.D. In Situ Electron Microscopy Electromechanical Characterization of a Bistable NEMS Device. Small 2006, 2, 1484-1489. [CrossRef] [PubMed]

68. Ernst, T.; Hentz, S.; Arcamone, J.; Agache, V.; Duraffourg, L.; Ouerghi, I.; Ludurczak, W.; Ladner, C.; Ollier, E.; Andreucci, P.; et al. High performance NEMS devices for sensing applications. In Proceedings of the 2015 45th European Solid-State Device Research Conference (ESSDERC), Graz, Austria, 14-18 September 2015; pp. 31-35.

69. Li, M.; Tang, H.X.; Roukes, M.L. Ultra-sensitive NEMS-based cantilevers for sensing, scanned probe and very high-frequency applications. Nat. Nanotechnol. 2007, 2, 114-120. [CrossRef] [PubMed]

70. Tao, Y.; Boss, J.M.; Moores, B.A.; Degen, C.L. Single-crystal diamond nanomechanical resonators with quality factors exceeding one million. Nat. Commun. 2014, 5. [CrossRef] [PubMed]

71. Davis, Z.J.; Abadal, G.; Helbo, B.; Hansen, O.; Campabadal, F.; Pérez-Murano, F.; Esteve, J.; Figueras, E.; Ruiz, R.; Barniol, N.; et al. High Mass and Spatial Resolution Mass Sensor based on Resonating Nano-Cantilevers Integrated with CMOS. In Transducers '01 Eurosensors XV; Obermeier, E., Ed.; Springer: Berlin/Heidelberg, Germany, 2001.

72. Wang, Y.-H.; Lee, C.-Y.; Chiang, C.-M. A MEMS-based Air Flow Sensor with a Free-standing Micro-cantilever Structure. Sensors 2007, 7, 2389-2401. [CrossRef] [PubMed]

73. Vajpayee, S.; Kumar, B.; Thakur, R.; Kumar, M. Design and Development of Nano pH Sensor and Interfacing with Arduino. Int. J. Electron. Electr. Comput. Syst. IJEECS 2017, 8, 6. [CrossRef]

74. Wang, J. Nanomachines: Fundamental and Application; Wiley: Hoboken, NJ, USA, 2013.

75. Yadav, V.; Duan, W.; Butler, P.J.; Sen, A. Anatomy of Nanoscale Propulsion. Annu. Rev. Biophys. 2015, 44, 77-100. [CrossRef]

76. Ren, L.; Zhou, D.; Mao, Z.; Xu, P.; Huang, T.J.; Mallouk, T.E. Rheotaxis of Bimetallic Micromotors Driven by Chemical-Acoustic Hybrid Power. ACS Nano 2017, 11, 10591-10598. [CrossRef]

77. Das, S.; Garg, A.; Campbell, A.I.; Howse, J.; Sen, A.; Velegol, D.; Golestanian, R.; Ebbens, S.J. Boundaries can steer active Janus spheres. Nat. Commun. 2015, 6. [CrossRef]

78. Duan, W.; Ibele, M.; Liu, R.; Sen, A. Motion analysis of light-powered autonomous silver chloride nanomotors. Eur. Phys. J. E 2012, 35. [CrossRef]

79. Wong, F.; Sen, A. Progress Towards Light-Harvesting Self-Electrophoretic Motors: Highly Efficient Bimetallic Nanomotors and Micropumps in Halogen Media. ACS Nano 2016, 10, 7172-7179. [CrossRef] [PubMed]

80. Duan, W.; Wang, W.; Das, S.; Yadav, V.; Mallouk, T.E.; Sen, A. Synthetic Nano- and Micromachines in Analytical Chemistry: Sensing, Migration, Capture, Delivery, and Separation. Annu. Rev. Anal. Chem. 2015, 8, 311-333. [CrossRef] [PubMed] 
81. Jurado-Sánchez, B.; Wang, J. Micromotors for environmental applications: A review. Environ. Sci. Nano Issue 2018, 5, 1530-1544. [CrossRef]

82. Ghosh, A.; Dasgupta, D.; Pal, M.; Morozov, K.; Lehshansky, A.; Ghosh, A. Helical Nano-machines as Mobile Viscometers. Adv. Funct. Mater. 2018, 28, 1705687. [CrossRef]

83. Hindi, S.S.Z. Molecular Machines: I. An Overview of Biological and Synthetic Angstromic Devices. Nanosci. Nanotechnol. Res. 2017, 4, 98-105.

84. Bamrungsap, S.; Phillips, J.A.; Xiong, X.; Kim, Y.; Wang, H.; Liu, H.; Hebard, A.; Tan, W. Magnetically driven single DNA nanomotor. Small 2011, 7, 601-605. [CrossRef] [PubMed]

85. Pal, M.; Somalwar, N.; Singh, A.; Bhat, R.; Eswarappa, S.M.; Saini, D.K.; Ghosh, A. Maneuverability of Magnetic Nanomotors Inside Living Cells. Adv. Mater. 2018, 30, 1800429. [CrossRef] [PubMed]

86. Dietrich-Buchecker, C.O.; Jimenez-Molero, M.C.; Sartor, V.; Sauvage, J.-P. Rotaxanes and catenanes as prototypes of molecular machines and motors. Pure Appl. Chem. 2003, 75, 1383-1393. [CrossRef]

87. Kudernac, T.; Ruangsupapichat, N.; Parschau, M.; Maciá, B.; Katsonis, N.; Harutyunyan, S.R.; Ernst, K.H.; Feringa, B.L. Electrically driven directional motion of a four-wheeled molecule on a metal surface. Nature 2011, 479, 208-211. [CrossRef] [PubMed]

88. Coskun, A.; Banaszak, M.; Astumian, R.D.; Stoddart, J.F.; Grzybowski, B.A. Great expectations: Can artificial molecular machines deliver on their promise? Chem. Soc. Rev. 2012, 41, 19-30. [CrossRef] [PubMed]

89. Bianco, B.; Moggia, E.; Giordano, S.; Rocchia, W.; Chiabrera, A. Friction and noise in quantum mechanics: A model for the interactions between a system and a thermal bath. Il Nuovo Cim. B 2001, 116, 155-165.

90. Farias, M.B.; Fosco, C.D.; Lombardo, F.C.; Mazzitelli, F.D. Quantum friction between graphene sheets. Phys. Rev. D 2017, 95, 065012. [CrossRef]

91. Jiang, Q.D.; Wilczek, F. Chiral Casimir forces: Repulsive, enhanced, tunable. Phys. Rev. B 2019, 99, 125403. [CrossRef]

92. Bennett, S.D.; Clerk, A.A. Laser-like instabilities in quantum nano-electromechanical systems. Phys. Rev. B 2006, 74, 201301. [CrossRef]

93. Cao, A.; Baskaran, R.; Frederick, M.; Turner, K.; Ajayan, P.; Ramanath, G. Direction-Selective and Length-Tunable In-Plane Growth of Carbon Nanotubes. Adv. Mater. 2003, 15, 1105-1109. [CrossRef]

94. Choi, J.; Pyo, S.; Baek, D.-H.; Lee, J.-I.; Kim, J. Thickness-, alignment- and defect-tunable growth of carbon nanotube arrays using designed mechanical loads. Carbon 2014, 66, 126-133. [CrossRef]

95. Hutchison, D.N.; Morrill, N.B.; Aten, Q.; Turner, B.W.; Jensen, B.D.; Howell, L.L.; Vanfleet, R.R.; Davis, R.C. Carbon Nanotubes as a Framework for High-Aspect-Ratio MEMS Fabrication. J. Microelectromech. Syst. 2010, 19, 75-82. [CrossRef]

96. Choi, J.; Lee, J.-I.; Eun, Y.; Kim, M.-O.; Kim, J. Aligned Carbon Nanotube Arrays for Degradation-Resistant, Intimate Contact in Micromechanical Devices. Adv. Mater. 2011, 23, 2231-2236. [CrossRef]

97. Choi, J.; Eun, Y.; Kim, J. Investigation of Interfacial Adhesion between the Top Ends of Carbon Nanotubes. ACS Appl. Mater. Interfaces 2014, 6, 6598-6605. [CrossRef]

98. Eun, Y.; Lee, J.I.; Choi, J.; Song, Y.; Kim, J. Integrated Carbon Nanotube Array as Dry Adhesive for High-Temperature Silicon Processing. Adv. Mater. 2011, 23, 2231-2236. [CrossRef]

99. Goold, J.; Huber, M.; Riera, A.; Del Rio, L.; Skrzypczyk, P. The role of quantum information in thermodynamics-A topical review. J. Phys. A Math. Theor. 2016, 49, 143001. [CrossRef]

100. Neuville, S. Transient Transversal Electric Field by Adsorbtion on Semiconductors. SNB 2007, $121,436$.

101. Caschera, D.; Federici, F.; Zane, D.; Focanti, F.; Curulli, A.; Padeletti, G. Gold nanoparticles modified GC electrodes: Electrochemical behavior dependence of different neurotransmitters and molecules of biological interest on the particles size and shape. J. Nanoparticle Res. 2009, 11, 1925. [CrossRef]

102. Krishnaraj, C.; Jagan, E.; Rajasekar, S.; Selvakumar, P.; Kalaichelvan, P.; Mohan, N. Synthesis of silver nanoparticles using Acalypha Indica leaf extracts and its antibacterial activity against water borne pathogens. Colloids Surf. B Biointerfaces 2010, 76, 50-56. [CrossRef] [PubMed]

103. Zhu, X.; Radovic-Moreno, A.F.; Wu, J.; Shi, R.L.J. Nano-medicine in the management of microbial infection overview and perspectives. Nano Today 2014, 9, 478-498. [CrossRef]

104. Waqar, A.; Abdelbary, E.; Vinod, D.; Karthikeyan, S. Emerging Nanotechnologies in Dentistry (Second Edition), Chapter 18-Carbon nanotubes: Applications in cancer therapy and drug delivery research. Micro Nano Technol. 2018, 371-389. [CrossRef] 
105. Sharifi, S.; Behzadi, S.; Laurent, S.; Forrest, M.L.; Stroeve, P.; Mahmoudi, M. Toxicity of nanomaterials. Chem. Soc. Rev. 2012, 41, 2323-2343. [CrossRef]

106. Ramsden, J.J. Assessing the toxic risks of the nanotechnology industry. Nanotechnol. Percept. 2013, 9, 119-134. [CrossRef]

107. Madani, S.Y.; Mandel, A.; Seifalian, A.M. A concise review of carbon nanotube's toxicology. Nano Rev. 2013, 4. [CrossRef]

108. Choi, J.; Kim, J. Batch-processed carbon nanotube wall as pressure and flow sensor. Nanotechnology 2010, 21, 105502. [CrossRef]

109. Hayamizu, Y.; Yamada, T.; Mizuno, K.; Davis, R.C.; Futaba, D.N.; Yumura, M.; Hata, K. Integrated three-dimensional micro-electromechanical devices from processable carbon nanotube wafers. Nat. Nanotechnol. 2008, 3, 289-294. [CrossRef]

110. Lee, J.I.; Eun, Y.; Choi, J.; Kwon, D.S.; Kim, J. Using Confined Self-Adjusting Carbon Nanotube Arrays as High-Sensitivity Displacement Sensing Element. ACS Appl. Mater. Interfaces 2014, 6, 10181-10187. [CrossRef]

111. Silva, S.P.R.; Carey, J.D.; Kahn, R.U.A.; Gerstner, E.G.; Anguita, J.V. Amorphous carbon thin films. In Handbook of Thin Film Materials; Nalwa, H.S., Ed.; Academic Press: New York, NY, USA, 2002; Chapter 9; Volume 4, pp. 403-505.

112. Casiraghi, C.; Robertson, J.; Ferrari, A. Review. Diamond Like Carbon for data storage and beer storage. Mater. Day 2007, 10, 44-53.

113. Huong, P.V. Structural studies of diamond films and ultrahard materials by Raman spectroscopy. Diam. Relat. Mater. 1991, 1, 31-41. [CrossRef]

114. Bachmann, P.K.; van Enckevort, W. Diamond deposition technologies. Diam. Relat. Mater. 1992, 1, $1021-1034$. [CrossRef]

115. Nimmagadda, R.R.; Joshi, J.; Hsu, L. Role of microstructure on the oxidation behavior of microwave plasma synthetized diamond and diamond like carbon. J. Mater. Res. 1990, 5, 2445-2450. [CrossRef]

116. McNamara, K.; Gleason, K.; Vestyck, D.; Butler, J.; Butler, J. Evaluation of diamond films by nuclear magnetic resonance and Raman spectroscopy. Diam. Relat. Mater. 1992, 1, 1145-1155. [CrossRef]

117. Fayette, L.; Marcus, B.; Mermoux, M.; Tourillon, G.; Laffon, K.; Parent, P.; Le Normand, F. Local order in CVD diamond films: Comparative Raman, $x$-ray-diffraction, and x-ray-absorption near-edge studies. Phys. Rev. B 1998, 57, 14123-14132. [CrossRef]

118. Hanada, K.; Nishiyama, T.; Yoshitake, T.; Nagayama, K. Time-Resolved Observation of Deposition Process of Ultra-nanocrystalline Diamond/Hydrogenated Amorphous Carbon Composite Films in Pulsed Laser Deposition. Hindawi J. Nanomater. 2009, 2009, 901241.

119. Hernberg, R.; Lepisto, T.; Mantyla, T.; Stenberg, T.; Vattulainen, J. Diamond film synthesis on Mo in thermal RF plasma. Diam. Relat. Mater. 1992, 1, 255-261. [CrossRef]

120. Kim, T.-Y.; Lee, C.S.; Lee, Y.J.; Lee, K.-R.; Chae, K.-H.; Oh, K.H. Reduction of the residual compressive stress of tetrahedral amorphous carbon film by Ar background gas during the filtered vacuum arc process. J. Appl. Phys. 2007, 101, 023504. [CrossRef]

121. Neuville, S. New applications perspectives on ta-C coating. QScience Connect 2014, 2014, 8. [CrossRef]

122. Reisse, G.; Weissmantel, S.; Rost, D. Preparation of super-hard coatings by pulsed laser deposition. Appl. Phys. A 2004, 79, 1275-1278. [CrossRef]

123. Shi, X.; Tay, B.K.; Lau, S.P. The Double Bent Filtered Cathodic Arc Technology and its Applications. Int. Mod. Phys. B 2000, 14, 136-153. [CrossRef]

124. Schultrich, B. Tetrahedrally Bonded Amorphous Carbon Films I: Basics, Structure and Preparation; Springer Nature: Berlin, Germany, 2018; 752p, ISBN 978-3-662-55927-7.

125. Charitidis, C.A. Nanomechanical and nanotribological properties of carbon-based thin films: A review. Int. J. Refract. Met. 2010, 28, 51-70. [CrossRef]

126. Sullivan, J.P.; Friedmann, T.A.; de Boer, M.P.; la Van, D.A.; Hohlfelder, R.J.; Ashby, C.I.H.; Dugger, M.T.; Mitchell, M.; Dunn, R.G.; Magerkurth, A.J. Developing a new material for MEMS: Amorphous diamond. In Proceedings of the Materials Research Society of MRS Fall Meating 2000 Symposium, Boston, MA, USA, USA, 27 November-1 December 2001; Volume 657.

127. Mel'nichenko, V.M.; Sladkov, A.M.; Nikulin, Y.N. Structure of Polymeric Carbon. In Russian Chemical Reviews; The British Library: London, UK, 1982; Volume 51. 
128. Li, X.; Masters, A.F.; Maschmeyer, T. Polymeric carbon nitride for solar hydrogen production. Chem. Commun. 2017, 53, 7438-7446. [CrossRef]

129. Bredas, J.L.; Street, G.B. Electronic structure of amorphous hydrogenated carbon films. In Proceedings of the Vol. XVII MRS Strasbourg Meeting, Strasbourg, France, 2 June 1987; Koidl, P., Oelhafen, P., Eds.; Les Editions de la Physique: Paris, France, 1987; pp. 237-250.

130. Wagner, J.; Ramsteiner, M.; Wild, C. Amorphous hydrogenated carbon films. In Proceedings of the Vol. XVII. MRS Strasbourg Meeting, Strasbourg, France, 2 June 1987; Koidl, P., Oelhafen, P., Eds.; Les Editions de la Physique: Paris, France, 1987; pp. 219-228.

131. Santra, T.S.; Bhattacharyya, T.K.; Patel, P.; Tseng, F.G.; Barik, T.K. Diamond, Diamond-Like Carbon (DLC) and Diamond-Like Nanocomposite (DLN) Thin Films for MEMS Applications. Microelectromech. Syst. D Devices 2012, 28, 459-480.

132. Badzian, A.R.; Bachmann, P.K.; Hartnett, T.; Badzian, T.; Messier, R. Diamond thin films prepared by PACVD processes. In Proceedings of the Vol. XVII MRS Strasbourg Meeting, Strasbourg, France, 2 June 1987; Koidl, P., Oelhafen, P., Eds.; Les Editions de la Physique: Paris, France, 1987; pp. 63-77.

133. Schueller, O.J.A.; Brittain, S.T.; Marzolin, C.; Whitesides, G.M. Fabrication and Characterization of Glassy Carbon MEMS. Chem. Mater. 1997, 9, 1399-1406. [CrossRef]

134. Chaudhury, S.; Sinha, S.K. Carbon Nanotube and Nanowires for Future Semiconductor Devices Applications. In Nanoelectronics; Kaush, B.K., Ed.; Devices, Circuits and Systems; Elsevier Inc.: Amsterdam, The Netherlands, 2018; Chapter 12, pp. 375-398, ISBN 978-0-12-813353.

135. Spencer, J.H.; Nesbitt, J.M.; Trewhitt, H.; Kashtiban, R.J.; Bell, G.; Ivanov, V.G.; Faulques, E.; Sloan, J.; Smith, D.C. Raman Spectroscopy of Optical Transitions and Vibrational Energies of $\sim 1 \mathrm{~nm} \mathrm{HgTe} \mathrm{Extreme}$ Nanowires within Single Walled Carbon Nanotubes. ACS Nano 2014, 8, 9044-9052. [CrossRef]

136. Lin, Y.Y.; Wei, H.W.; Leou, K.C.; Lin, H.; Tung, C.H.; Wei, M.T.; Lin, C.; Tsai, C.H. Experimental characterization of an inductively coupled acetylene/hydrogen plasma for Carbon Nano Fiber synthesis (CNF). J. Vac. Sci. Technol. B 2006, 24, 97-112. [CrossRef]

137. Iijima, S. Synthesis of Carbon Nanotubes. Nature 1991, 354, 56-58. [CrossRef]

138. Endo, M.; Strano, M.S.; Ajayan, P.M. Potential Applications of Carbon Nanotubes. In Carbon Nanotubes; Jorio, A., Dresselhaus, G., Dresselhaus, M.S., Eds.; Topics in Applied Physics; Springer: New York, NY, USA, USA, 2007; pp. 13-62, ISBN 978-3-540-72864-1.

139. Endo, M.; Iijima, S.; Dresselhaus, M.S. Carbon Nanotubes; Elsevier: Amsterdam, The Netherlands, 1997; 198p, ISBN 9780080426822.

140. Küttel, O.M.; Gröning, O.; Emmenegger, C.; Nilsson, L.; Maillard, E.; Diederich, L.; Schlapbach, L. Field emission from diamond, diamond-like and nanostructured carbon films. Carbon 1999, 37, 745-752. [CrossRef]

141. Giubileo, F.; di Bartolomeo, A.; Iemmo, L.; Luongo, G.; Urban, F. Field Emission from Carbon Nanostructures. Appl. Sci. 2018, 8, 526. [CrossRef]

142. Fedoseeva, Y.V.; Bulusheva, L.G.; Okotrub, A.V.; Kanygin, M.A.; Gorodetskiy, D.V.; Asanov, I.P.; Vyalikh, D.V.; Puzyr, A.P.; Bondar, V.S. Field Emission Luminescence of Nano-Diamonds Deposited on the Aligned Carbon Nanotube Array. Sci. Rep. 2015, 5, 9379. [CrossRef]

143. Bonard, J.M.; Weiss, N.; Kind, H.; Stöckli, T.; Forró, L.; Kern, K.; Châtelain, A. Tuning the Field Emission Properties of Patterned Carbon Nanotube Films. Adv. Mater. 2001, 13, 184-188. [CrossRef]

144. Clark, I.T.; Yoshimura, M. Electronic properties of carbon nanotube. In Fabrication of Carbon Nanotubes for High-Performance Scanning Probe Microscopy; Intechopen: London, UK, 2011; pp. 91-104.

145. Tanaka, K.; Yoshimura, M.; Ueda, K. High-Resolution Magnetic Force Microscopy Using Carbon Nanotube Probes Fabricated Directly by Microwave Plasma-Enhanced Chemical Vapor Deposition. J. Nanomater. 2009, 2009. [CrossRef]

146. Laocharoensuk, R.; Burdick, J.; Wang, J. Carbon-Nanotube-Induced Acceleration of Catalytic Nanomotors. ACS Nano 2008, 2, 1069-1075. [CrossRef]

147. Inami, N.; Shikoh, E.; Mohamed, M.A.; Fujiwara, A. Synthesis-condition dependence of carbon nanotube growth by alcohol catalytic chemical vapor deposition method. Sci. Technol. Adv. Mater. 2007, 8, 292-295. [CrossRef]

148. Hermann, S.; Ecke, R.; Schulz, S.; Gessner, T. Controlling the formation of nanoparticles for definite growth of carbon nanotubes for interconnect applications. Microelectron. Eng. 2008, 85, 1979-1983. [CrossRef] 
149. Costa, S.; Borowiak-Palen, E.; Kruszynska, M.; Bachmatiuk, A.; Kalenczuk, R.J. Characterization of carbon nanotubes by Raman spectroscopy. Mater. Sci. Pol. 2008, 26, 433-441.

150. Dresselhaus, M.; Dresselhaus, G.; Saito, R.; Jorio, A. Raman spectroscopy of carbon nanotubes. Phys. Rep. 2005, 409, 47-99. [CrossRef]

151. Malard, L.M.; Pimenta, M.A.; Dresselhaus, G.; Dresselhaus, M.S. Raman spectroscopy in graphene. Phys. Rep. 2009, 473, 51-87. [CrossRef]

152. Ritter, K.A.; Lyding, J.W. The influence of edge structure on the electronic properties of graphene quantum dots and nanoribbons. Nat. Mater. 2009, 8, 235-242. [CrossRef] [PubMed]

153. Begliarbekov, M.; Sul, O.; Kalliakos, S.; Yang, E.-H.; Strauf, S. Determination of edge purity in bilayer graphene using $\mu$-Raman spectroscopy. Appl. Phys. Lett. 2010, 97, 31908. [CrossRef]

154. You, Y.; Ni, Z.; Yu, T.; Shen, Z. Edge chirality determination of graphene by Raman spectroscopy. Appl. Phys. Lett. 2008, 93, 163112. [CrossRef]

155. Xu, Y.N.; Zhan, D.; Liu, L.; Suo, H.; Ni, Z.H.; Nguyen, T.T.; Zhao, C.; Shen, Z.X. Thermal Dynamics of Graphene Edges Investigated by Polarized Raman Spectroscopy. ACS Nano 2011, 5, 142-152. [CrossRef] [PubMed]

156. Iakoubovskii, K.; Minami, N.; Ueno, T.; Kazaoui, S.; Kataura, H. Optical Characterization of Double-Wall Carbon Nanotubes: Evidence for Inner Tube Shielding. J. Phys. Chem. C 2008, 112, 11194-11198. [CrossRef]

157. Mogensen, K.B.; Kutter, J.P. Carbon nanotube based stationary phases for microchip chromatography. Lab Chip 2012, 12, 1951-1958. [CrossRef] [PubMed]

158. Bachilo, S.M. Structure-Assigned Optical Spectra of Single-Walled Carbon Nanotubes. Science 2002, 298, 2361-2366. [CrossRef] [PubMed]

159. Cherukuri, P.; Bachilo, S.M.; Litovsky, S.H.; Weisman, R.B. Near-Infrared Fluorescence Microscopy of Single-Walled Carbon Nanotubes in Phagocytic Cells. J. Am. Chem. Soc. 2004, 126, 15638-15639. [CrossRef]

160. Yum, K.; McNicholas, T.P.; Mu, B.; Strano, M.S. Single-Walled Carbon Nanotube-Based Near-Infrared Optical Glucose Sensors toward In Vivo Continuous Glucose Monitoring. J. Diabetes Sci. Technol. 2013, 7, $72-87$. [CrossRef] [PubMed]

161. He, X.; Wang, X.; Nanot, S.; Cong, K.; Jiang, Q.; Kane, A.A.; Goldsmith, J.E.M.; Hauge, R.H.; Leonard, F.; Kono, J. Photo-thermoelectric p-n junction photodetector with intrinsic broadband polarimetry based on macroscopic carbon nanotube films. ACS Nano 2013, 7, 7271-7277. [CrossRef] [PubMed]

162. Janas, D.; Herman, A.P.; Boncel, S.; Koziol, K.K. Iodine monochloride as a powerful enhancer of electrical conductivity of carbon nanotube wires. Carbon 2014, 73, 225-233. [CrossRef]

163. Zhao, Y.; Wei, J.; Vajtai, R.; Ajayan, P.M.; Barrera, E.V. Iodine doped carbon nanotube cables exceeding specific electrical conductivity of metals. Sci. Rep. 2011, 1. [CrossRef] [PubMed]

164. Subramaniam, C.; Yamada, T.; Kobashi, K.; Sekiguchi, A.; Futaba, D.N.; Yumura, M.; Hata, K. One-hundredfold increase in current carrying capacity in a carbon nanotube-copper composite. Nat. Commun. 2013, 4. [CrossRef] [PubMed]

165. Kim, I.T.; Tannenbaum, A.; Tannenbaum, R. Anisotropic conductivity of magnetic carbon nanotubes embedded in epoxy matrices. Carbon 2011, 49, 54-61. [CrossRef] [PubMed]

166. Wu, Z.-S.; Ren, W.; Xu, L.; Li, F.; Cheng, H.-M. Doped Graphene Sheets as Anode Materials with Superhigh Rate and Large Capacity for Lithium Ion Batteries. ACS Nano 2011, 5, 5463-5471. [CrossRef]

167. Javey, A.; Guo, J.; Farmer, D.B.; Wang, Q.; Yenilmez, E.; Gordon, R.G.; Lundstrom, M.; Dai, H. Self-Aligned Ballistic Molecular Transistors and Electrically Parallel Nanotube Arrays. Nano Lett. 2004, 4, 1319-1322. [CrossRef]

168. Hasan, S.; Salahuddin, S.; Vaidyanathan, M.; Alam, M.A. High frequency performance projections for ballistic carbon nano-tube transistors. IEEE Trans. Nanotechnol. 2006, 5, 14-22. [CrossRef]

169. Ritter, U.; Scharff, P.; Sigmund, C.; Dimmytrenko, O.; Kulish, N.; Prylutskyy, Y.; Belyi, N.; Gubanov, V.; Komarova, L.; Lizunova, S.; et al. Radiation damage to multi-walled carbon nanotubes and their Raman vibrational modes. Carbon 2006, 44, 2694-2700. [CrossRef]

170. Dresselhaus, M.S.; Jorio, A.; Filho, A.G.S.; Saito, R. Defect characterization in graphene and carbon nanotubes using Raman spectroscopy. Philos. Trans. R. Soc. A Math. Phys. Eng. Sci. 2010, 368, 5355-5377. [CrossRef] [PubMed]

171. Banhart, F.; Kotakoski, J.; Krasheninnikov, A.V. Structural Defects in Graphene. ACS Nano 2011, 5, $26-41$. [CrossRef] [PubMed] 
172. Campos-Delgado, J.; Kim, Y.A.; Hayashi, T.; Morelos-Gomez, A.; Hofmann, M.; Muramatsu, H.; Endo, M.; Terrones, H.; Shull, R.D.; Dresselhaus, M.S.; et al. Thermal stability studies of CVD-grown graphene nanoribbons: Defect annealing and loop formation. Chem.Phys. Lett. 2009, 469, 177-182. [CrossRef]

173. Huong, P.V.; Marcus, B.; Mermoux, M.; Veirs, D.K.; Rosenblatt, G.M. Diamond-like films prepared by microwave plasma assisted chemical vapor deposition and by magnetron sputtering. Diam. Relat. Mater. 1992, 1, 869-873. [CrossRef]

174. Flamant, G.; Guillard, R.; Laplaz, D. La synthese des fullerenes par energie solaire. Le Vide 2001, 2-4, 266.

175. Sato, F. Diamond-like bonds in amorphous hydrogenated carbon films induced by x-ray irradiation. J. Vac. Sci. Technol. A 1998, 16, 2553-2555. [CrossRef]

176. Balat-Pichelin, M.; Eck, J.; Sans, J. Thermal radiative properties of carbon materials under high temperature and vacuum ultra-violet (VUV) radiation for the heat shield of the Solar Probe Plus mission. Appl. Surf. Sci. 2012, 258, 2829-2835. [CrossRef]

177. Matsui, Y.; Yabe, H.; Sugimoto, T.; Hirose, Y. The structure of acetylene flames for diamond synthesis. Diam. Relat. Mater. 1991, 1, 19-24. [CrossRef]

178. Hinneberg, H.-J.; Eck, M.; Schmidt, K. Hot-filament-grown diamond films on Si: Characterization of impurities. Diam. Relat. Mater. 1992, 1, 810-813. [CrossRef]

179. Smith, D.; Sevillano, E.; Besen, M.; Berkman, V.; Bourget, L. Large area diamond reactor using a high flow velocity microwave plasma jet. Diam. Relat. Mater. 1992, 1, 814-817. [CrossRef]

180. Schultrich, B.; Scheibe, H.-J.; Drescher, D.; Ziegele, H. Deposition of superhard amorphous carbon films by pulsed vacuum arc deposition. Surf. Coat. Technol. 1998, 98, 1097-1101. [CrossRef]

181. Liu, D.; Tu, J.; Hong, C.; Gu, C.; Mao, S. Two-phase nanostructured carbon nitride films prepared by direct current magnetron sputtering and thermal annealing. Surf. Coat. Technol. 2010, 205, 152-157. [CrossRef]

182. Iwaki, M.; Takahashi, K.; Sekiguchi, A. Wear property and structure of implanted glassy carbon. J. Mater. Res. 1990, 5, 2562-2566. [CrossRef]

183. Wang, Z.; Wang, C.; Wang, Q.; Zhang, J. Annealing effect on the microstructure modification and tribological properties of amorphous carbon nitride films. J. Appl. Phys. 2008, 104, 073306. [CrossRef]

184. Li, J.; Zheng, W.; Bian, H.J.; Lu, X.Y.; Jiang, Z.G.; Bai, Y.Z.; Jin, Z.S.; Zhao, Y.N. The effect of annealing on the field emission properties of amorphous CNx films. Acta Phys. Sin. 2003, 52, 1797-1801.

185. Borroni-Bird, C.E.; King, D.A. An ultrahigh vacuum single crystal adsorption micro-calorimeter. Rev. Sci. Instrum. 1991, 62, 2177-2185. [CrossRef]

186. Sankara-Reddy, K.S.; Satyam, M. Structural ordering of diamond like carbon films by applied electric field. Solid State Commun. 1995, 93, 797-799. [CrossRef]

187. De Padova, P.; Quaresima, C.; Ottaviani, C.; Sheverdyaeva, P.M.; Moras, P.; Carbone, C.; Topwal, D.; Olivieri, B.; Kara, A.; Oughaddou, H.; et al. Evidence of graphene-like electronic signature in silicene nanoribbons. Appl. Phys. Lett. 2010, 96, 261905. [CrossRef]

188. Endo, M.; Kim, Y.A.; Matusita, T.; Hayashi, T. From Vapor-Grown Carbon Fibers (VGCFs) to Carbon Nanotubes. In Carbon Filaments and Nanotubes: Common Origins, Differing Applications? NATO Science Series (Series E: Applied Sciences); Biró, L.P., Bernardo, C.A., Tibbetts, G.G., Lambin, P., Eds.; Springer: Dordrecht, The Netherlands, 2001; Volume 372, ISBN 978-0-7923-6908.

189. Spear, K.E.; Phelps, A.W.; White, W.B.; Phelps, A. Diamond polytypes and their vibrational spectra. J. Mater. Res. 1990, 5, 2277-2285. [CrossRef]

190. Phelps, A.W.; Howard, W.; White, W.B.; Spear, K.E.; Huang, D. Diamond, Boron Nitride, Silicon Carbide, and Related Wide Bandgap Semiconductors. In Proceedings of the Materials Research Society Symposium, Boston, MA, USA, 27 Novermber-1 December 1989; Glass, J.T., Messier, R.F., Fujimori, N., Eds.; Materials Research Society: Pittsburgh, PA, USA, 1989.

191. Beeman, D.; Silverman, J.; Lynds, R.; Anderson, M.R. Modeling studies of amorphous carbon. Phys. Rev. B 1984, 30, 870-875. [CrossRef]

192. Sønderby, S.; Berthelsen, A.; Almtoft, K.; Christensen, B.; Nielsen, L.; Bøttiger, J. Optimization of the mechanical properties of magnetron sputtered diamond-like carbon coatings. Diam. Relat. Mater. 2011, 20, 682-686. [CrossRef]

193. Ohl, A.; Röpke, J. Mechanism of substrate heating in diamond-forming low-pressure microwave discharges. Diam. Relat. Mater. 1992, 1, 243-247. [CrossRef] 
194. Neuville, S. The enhancement of interconnected sp3 sites by chemical effects during ta-C film growth. Diam. Relat. Mater. 2002, 11, 1721-1730. [CrossRef]

195. Wang, X.H.; Ma, G.H.M.; Zhu, W.; Glass, J.T.; Bergman, L.; Turner, K.F.; Nemanich, R.J. Effect of Boron doping on the surface morphology of and structural imperfection of diamond films. Diam. Relat. Mater. 1992, 1, 828-835. [CrossRef]

196. Zhou, C.; Chen, S.; Lou, J.; Wang, J.; Yang, Q.; Liu, C.; Huang, D.; Zhu, T. Graphene's cousin: The present and future of graphane. Nanoscale Res. Lett. 2014, 9. [CrossRef] [PubMed]

197. Elias, D.C.; Nair, R.R.; Mohiuddin, T.M.; Morozov, S.V.; Blake, P.; Halsall, M.P.; Ferrari, A.C.; Boukhvalov, D.W.; Katsnelson, M.I.; Geim, A.K.; et al. Control of graphene's properties by reversible hydrogenation: Evidence for graphane. Science 2009, 323, 610-613. [CrossRef] [PubMed]

198. Tolédano, J.C.; Tolédano, P. The Landau Theory of Phase Transitions; World Scientific: Singapore, 1987; ISBN 9971-50-025-6.

199. Sofo, J.O.; Chaudhari, A.S.; Barber, G.D. Graphane: A two-dimensional hydrocarbon. Phys. Rev. B 2007, 75, 153401. [CrossRef]

200. Podlivaev, A.I.; Openov, L.A. Elementary Defects in Graphane. JETP Lett. 2017, 106, 110-115. [CrossRef]

201. Poh, H.L.; Šaněk, F.; Sofer, Z.; Pumera, M. High-pressure hydrogenation of graphene: Towards graphane. Nanoscale 2012, 4, 7006-7011. [CrossRef]

202. Liu, A.Y.; Cohen, M.L. Structural properties and electronic structure of low-compressibility materials: $\beta$-Si3N4 and hypothetical $\beta$-C3N4. Phys. Rev. B 1990, 41, 10727. [CrossRef]

203. Cao, S.; Yu, J. g-C 3 N 4 -Based Photocatalysts for Hydrogen Generation. J. Phys. Chem. Lett. 2014, 5, $2101-2107$. [CrossRef] [PubMed]

204. Collins, P.G.; Bradley, K.; Ishigami, M.; Zettl, A. Extreme Oxygen Sensitivity of Electronic Properties of Carbon Nanotubes. Science 2000, 287, 1801-1804. [CrossRef] [PubMed]

205. Al-Mumen, H.; Rao, F.; Li, W.; Dong, L. Singular Sheet Etching of Graphene with Oxygen Plasma. NanoMicro Lett. 2014, 6, 116-124. [CrossRef]

206. Czech, B.; Oleszczuk, P.; Wiacek, A.E.; Barczak, M. Cracking of CNT wall by UV. Environ. Sci. Pollut. Res. 2015, 22, 20198-20206. [CrossRef] [PubMed]

207. Neuville, S. Perspective of low energy Bethe nuclear fusion reactor with quantum electronic atomic rearrangement of carbon. Condens. Matter. Nucl. Sci. 2017, 22, 1-26.

208. Rouzaud, J.; Oberlin, A.; Beny-Bassez, C. Carbon films: Structure and micro-texture (optical and electron microscopy, Raman spectroscopy). Thin Solid Film. 1983, 105, 75-96. [CrossRef]

209. Anders, S.; Iii, J.W.A.; Pharr, G.M.; Tsui, T.Y.; Brown, I.G. Heat treatment of cathodic arc deposited amorphous hard carbon films. Thin Solid Film. 1997, 308, 186-190. [CrossRef]

210. Prawer, S.; Nugent, K.; Lifshitz, Y.; Lempert, G.; Grossman, E.; Kulik, J.; Avigal, I.; Kalish, R. Systematic variation of the Raman spectra of DLC films as a function of sp2: sp3 composition. Diam. Relat. Mater. 1996, 5, 433-438. [CrossRef]

211. Ferrari, A.C. Determination of bonding in diamond-like carbon by Raman spectroscopy. Diam. Relat. Mater. 2002, 11, 1053-1061. [CrossRef]

212. Rammamurti, R.; Shanov, V.; Singh, R.N.; Mamedov, S.; Boolchand, P. Raman spectroscopy study of the influence of processing conditions on the structure of polycrystalline diamond films. J. Vac. Sci. Technol. A 2006, 24, 179. [CrossRef]

213. Tuinstra, F.; Koenig, J.L. Raman spectra of graphite. J. Phys. Chem. 1970, 53, 1126-1130. [CrossRef]

214. Robertson, J.; O'Reilly, E.P. Electronic and atomic structure of amorphous carbon. Phys. Rev. B 1987, 35, 2946-2957. [CrossRef] [PubMed]

215. Pauleau, Y. Residual Stresses in DLC Films and Adhesion to Various Substrates. In Tribology of DLC; Donnet, C., Erdemir, A., Eds.; Springer: New York, NY, USA, 2008; pp. 102-136.

216. Maultzsch, J.; Reich, S.; Thomsen, C. Double-resonant Raman scattering in graphite: Interference effects, selection rules, and phonon dispersion. Phys. Rev. B 2004, 70, 155403. [CrossRef]

217. Jorio, A. Raman Spectroscopy in Graphene-Based Systems: Prototypes for Nanoscience and Nanometrology. Int. Sch. Res. Netw. ISRN Nanotechnol. 2012, 2012, 234216. [CrossRef]

218. Watanabe, E.; Conwill, A.; Tsuya, D.; Koide, Y. Low contact resistance metals for graphene-based devices. Diam. Relat. Mater. 2012, 24, 171-174. [CrossRef] 
219. Reina, A.; Jia, X.; Ho, J.; Nezich, D.; Son, H.; Bulović, V.; Dresselhaus, M.S.; Kong, J. Large Area, Few-Layer Graphene Films on Arbitrary Substrates by Chemical Vapor Deposition. Nano Lett. 2009, 9, 30-35. [CrossRef] [PubMed]

220. Kumar, P.; Wani, M.F. Synthesis and tribological properties of graphene: A review. J. Tribol. 2017, $13,36-71$.

221. Penkov, O.; Kim, H.J.; Kim, H.J.; Kim, D.E. Tribology of Graphene: A Review. Int. J. Precis. Eng. Manuf. 2014, 15, 577-585. [CrossRef]

222. Cançado, C.L.G.; Pimenta, M.A.; Neves, B.R.; Dantas, M.S.; Jorio, A. Influence of the Atomic Structure on the Raman Spectra of Graphite Edges. Phys. Rev. Lett. 2004, 93, 247401. [CrossRef] [PubMed]

223. Dischler, B. Bonding and hydrogen incorporation in a-C: $\mathrm{H}$ studied by infrared spectroscopy. In EMRS XVII Proceedings; Koidl, P., Oelhafen, P., Eds.; Les Editions de la Physique: Paris, France, 1987; pp. 189-201.

224. Marcus, B.; Fayette, L.; Mermoux, M.; Abello, L.; Lucazeau, G. Analysis of the structure of multi-component carbon films by resonant Raman scattering. J. Appl. Phys. 1994, 76, 3463-3470. [CrossRef]

225. Singh, R.C.V. Raman and the Discovery of the Raman Effect. Phys. Perspect. 2002, 4, 399-420. [CrossRef]

226. Saito, R.; Jorio, A.; Filho, A.G.S.; Dresselhaus, G.; Dresselhaus, M.S.; Pimenta, M.A. Probing Phonon Dispersion Relations of Graphite by Double Resonance Raman Scattering. Phys. Rev. Lett. 2001, 88, 027401. [CrossRef] [PubMed]

227. Lazzeri, M.; Attaccalite, C.; Wirtz, L.; Mauri, F. Impact of the electron-electron correlation on phonon dispersion: Failure of LDA and GGA DFT functionals in graphene and graphite. Phys. Rev. B 2008, 78, 081406. [CrossRef]

228. Dallas, T.E.J. Thesis on Structural Phases of Disordered Carbon Materials. Ph.D. Thesis, Texas Tech University, Lubbock, TX, USA, 1996.

229. Chivilikhin, S.A.; Gusarov, V.V.; Yu-Popov, I. Flows in nanostructures: Hybrid classical-quantum models. Nano-Syst. Phys. Chem. Math. 2012, 3, 7-26.

230. Piscanec, S.; Lazzeri, M.; Mauri, F.; Ferrari, A.C.; Robertson, J. Kohn Anomalies and Electron-Phonon Interactions in Graphite. Phys. Rev. Lett. 2004, 93, 185503. [CrossRef] [PubMed]

231. Fakrach, B.; Rahmani, A.; Chadli, H.; Sbai, K.; Sauvajol, J.L. Raman spectrum of single-walled boron nitride nanotube. Physica E 2009, 41, 1800-1805. [CrossRef]

232. Lee, S. Effect of Intrinsic Ripples on Elasticity of the Graphene Monolayer. Nanoscale Res. Lett. 2015, 10, 1704. [CrossRef]

233. Nicholl, R.J.T.; Conley, H.J.; Lavrik, N.V.; Vlassiouk, I.; Puzyrev, Y.S.; Sreenivas, V.P.; Pantelides, S.T.; Bolotin, K.I. The effect of intrinsic crumpling on the mechanics of free-standing graphene. Nat. Commun. 2015, 6. [CrossRef]

234. Thompson-Flagg, R.C.; Moura, M.J.B.; Marder, M. Rippling of graphene. EPL (Europhys. Lett.) $2009,85$. [CrossRef]

235. Tanigaki, K.; Ogi1, H.; Sumiya, H.; Kusakabe, K.; Nakamura, N.; Hirao, M.; Ledbetter, H. Observation of higher stiffness in nano-polycrystal diamond than monocrystal diamond. Nat. Commun. 2013. [CrossRef]

236. Gómez-Navarro, C.; Weitz, R.T.; Bittner, A.M.; Scolari, M.; Mews, A.; Burghard, M.; Kern, K. Electronic Transport Properties of Individual Chemically Reduced Graphene Oxide Sheets. Nano Lett. 2007, 7, 3499-3503. [CrossRef] [PubMed]

237. Childres, I.; A Jauregui, L.; Tian, J.; Chen, Y.P. Effect of oxygen plasma etching on graphene studied using Raman spectroscopy and electronic transport measurements. New J. Phys. 2011, 13, 25008. [CrossRef]

238. Janas, D. Towards monochiral carbon nanotubes: A review of progress in the sorting of single-walled carbon nanotubes. Mater. Chem. Front. 2018, 2, 36-63. [CrossRef]

239. Green, A.A.; Duch, M.C.; Hersam, M.C. Isolation of single-walled carbon nanotube enantiomers by density differentiation. Nano Res. 2009, 2, 69-77. [CrossRef]

240. Neuville, S. Prebiotic mechanisms of life appearance near deep sea vents with early earth synthetized L-handed amino acids being adsorbed on SWCNT. Q. Phys. Rev. 2018, 4, 1-36.

241. De Volder, M.F.L.; Tawfick, S.H.; Baughman, R.H.; Hart, A.J. Carbon Nanotubes: Present and Future Commercial Applications. Science 2013, 339, 535-539. [CrossRef] [PubMed]

242. Li, Z.; Guo, Q.; Li, Z.; Fan, G.; Xiong, D.B.; Su, Y.; Zhang, J.; Zhang, D. Enhanced Mechanical Properties of Graphene (Reduced Graphene Oxide)/Aluminum Composites with a Bioinspired Nano-laminated Structure. Nano Lett. 2015, 15, 8077-8083. [CrossRef]

243. Zhang, M.; Knoch, D.; Pascual-Leone, A.; Meyer, K.; Treyer, V.; Fehr, E. Strong, Transparent, Multifunctional, Carbon Nanotube Sheets. Science 2005, 309, 1215-1219. [CrossRef] 
244. Coleman, J.N.; Khan, U.; Blau, W.J.; Gun'Ko, Y.K. Small but strong: A review of the mechanical properties of carbon nanotube-polymer composites. Carbon 2006, 44, 1624-1652. [CrossRef]

245. Kim, K.H.; Oh, Y.; Islam, M.F.; Islam, M. Graphene coating makes carbon nanotube aerogels superelastic and resistant to fatigue. Nat. Nanotechnol. 2012, 7, 562-566. [CrossRef]

246. Poelma, R.H.; Morana, B.; Vollebregt, S.; Schlangen, E.; Van Zeijl, H.W.; Fan, X.; Zhang, G.Q. Tailoring the Mechanical Properties of High-Aspect-Ratio Carbon Nanotube Arrays using Amorphous Silicon Carbide Coatings. Adv. Funct. Mater. 2014, 24, 5737-5744. [CrossRef]

247. Watcharotone, S.; Dikin, D.A.; Stankovich, S.; Piner, R.; Jung, I.; Dommett, G.H.B.; Evmenenko, G.; Wu, S.E.; Chen, S.F.; Liu, C.P.; et al. Graphene-Silica Composite Thin Films as Transparent Conductors. Nano Lett. 2007, 7, 1888-1892. [CrossRef] [PubMed]

248. Susantyoko, R.A.; Alkindi, T.S.; Kanagaraj, A.B.; An, B.; Alshibli, H.; Choi, D.; Aldahmani, S.; Fadaq, H.; Almheiri, S. Performance optimization of freestanding MWCNT-LiFePO4 sheets as cathodes for improved specific capacity of lithium-ion batteries. RSC Adv. 2018, 8, 16566-16573. [CrossRef]

249. Lalwani, G.; Kwaczala, A.T.; Kanakia, S.; Patel, S.C.; Judex, S.; Sitharaman, B. Fabrication and characterization of three-dimensional macroscopic all-carbon scaffolds. Carbon 2013, 53, 90-100. [CrossRef] [PubMed]

250. Van Der Zande, A.M.; Verbridge, S.S.; Frank, I.W.; Tanenbaum, D.M.; Parpia, J.M.; Craighead, H.G.; McEuen, P.L.; Bunch, J.S. Electromechanical Resonators from Graphene Sheets. Science 2007, 315, 490-493.

251. Xiao, L.; Chen, Z.; Feng, C.; Liu, L.; Bai, Z.-Q.; Wang, Y.; Qian, L.; Zhang, Y.; Li, Q.; Jiang, K.; et al. Flexible, Stretchable, Transparent Carbon Nanotube Thin Film Loudspeakers. Nano Lett. 2008, 8, 4539-4545. [CrossRef]

252. Zhang, J.-C.; Tang, Y.-J.; Yi, Y.; Ma, K.-F.; Zhou, M.-J.; Wu, W.-D.; Wang, C.-Y. Large-scale synthesis of novel vertically-aligned helical carbon nanotube arrays. New Carbon Mater. 2016, 31, 568-573. [CrossRef]

253. Aliev, A.E.; Oh, J.; Kozlov, M.E.; Kuznetsov, A.A.; Fang, S.; Fonseca, A.F.; Ovalle, R.; Lima, M.D.; Haque, M.H.; Gartstein, Y.N.; et al. Giant-Stroke, Superelastic Carbon Nanotube Aerogel Muscles. Science 2009, 323, 1575-1578. [CrossRef]

254. Du, S. A microelectromechanical system based inertial system with rotating accelerometers and gyroscope for Land navigation systems. Int. J. Distrib. Sens. Netw. 2017, 13. [CrossRef]

255. Miller, D.C.; Foster, R.R.; Zhang, Y.; Jen, S.H.; Bertrand, J.A.; Lu, Z.; Seghete, D.; O’Patchen, J.L.; Lee, R.Y.Y.C.; George, S.M.; et al. The mechanical robustness of atomic-layer- and molecular-layer-deposited coatings on polymer substrates. J. Appl. Phys. 2009, 105. [CrossRef]

256. Berman, D.; Erdemir, A.; Sumant, A.V. Reduced wear and friction enabled by graphene layers on sliding steel surfaces in dry nitrogen. Carbon 2013, 59, 167-175. [CrossRef]

257. Yan, C.; Kim, K.S.; Lee, S.K.; Bae, S.H.; Hong, B.H.; Kim, J.H.; Lee, H.J.; Ahn, J.H. Mechanical and Environmental Stability of Polymer Thin-Film-Coated Graphene. ACS Nano 2012, 6, 2096-2103. [CrossRef] [PubMed]

258. Marchetto, D.; Held, C.; Hausen, F.; Wählisch, F.; Dienwiebel, M.; Bennewitz, R. Friction and Wear on Single-Layer Epitaxial Graphene in Multi-Asperity Contacts. Tribol. Lett. 2012, 48, 77-82. [CrossRef]

259. Naraghi, M.; Filleter, T.; Moravsky, A.; Locascio, M.; Loutfy, R.O.; Espinosa, H.D. A Multiscale Study of High-Performance Double-Walled Nanotube-Polymer Fibers. ACS Nano 2010, 4, 6463-6476. [CrossRef] [PubMed]

260. Yildirim, T.; Gülseren, O.; Kılıç, C.; Ciraci, S. Pressure-induced interlinking of carbon nanotubes. Phys. Rev. B 2000, 62. [CrossRef]

261. Zhang, R.; Zhang, Y.; Zhang, Q.; Xie, H.; Qian, W.; Wei, F. Growth of Half-Meter Long Carbon Nanotubes Based on Schulz-Flory Distribution. ACS Nano 2013, 7, 6156-6161. [CrossRef] [PubMed]

262. Motta, M.; Moisala, A.; Kinloch, I.A.; Windle, A.H. High Performance Fibers from 'Dog Bone' Carbon Nanotubes. Adv. Mater. 2007, 19, 3721-3726. [CrossRef]

263. Dalton, A.B.; Collins, S.; Muñoz, E.; Razal, J.M.; Ebron, V.H.; Ferraris, J.P.; Coleman, J.N.; Kim, B.G.; Baughman, R.H. Super-tough carbon-nanotube fibers. Nature 2003, 423. [CrossRef]

264. Yang, Y.; Chen, X.; Shao, Z.; Zhou, P.; Porter, D.; Knight, D.P.; Vollrath, F. Toughness of Spider Silk at High and Low Temperatures. Adv. Mater. 2005, 17, 84-88. [CrossRef]

265. Behabtu, N.; Young, C.C.; Tsentalovich, D.E.; Kleinerman, O.; Wang, X.; Ma, A.W.K.; Bengio, E.A.; Ter Waarbeek, R.F.; De Jong, J.J.; Hoogerwerf, R.E.; et al. Strong, Light, Multifunctional Fibers of Carbon Nanotubes with Ultrahigh Conductivity. Science 2013, 339, 182-186. [CrossRef] 
266. Liu, G.; Zheng, H.; Jiang, Z.; Zhao, J.; Wang, Z.; Pan, B.; Xing, B. Formation and Physicochemical Characteristics of Nano Biochar: Insight into Chemical and Colloidal Stability. Environ. Sci. Technol. 2018, 52, 10369-10379. [CrossRef] [PubMed]

267. Giorcelli, M.; Savi, P.; Khan, A.; Tagliaferro, A. Analysis of biochar with different pyrolysis temperatures used as filler in epoxy resin composites. Biomass Bioenergy 2019, 122, 466-471. [CrossRef]

268. Srivastava, N.; Joshi, R.; Banerjee, K. Carbon nanotube interconnects: Implications for performance, power dissipation and thermal management. In Proceedings of the IEEE International Electron Devices Meeting, Washington, DC, USA, 5 December 2005; IEDM Technical Digest. IEEE: Piscataway, NJ, USA, 2005; p. 249, ISBN 0-7803-9268-X.

269. Coiffic, J.C.; Fayolle, M.; Maitrejean, S.; Torres, L.E.F.F.; Le Poche, H. Conduction regime in innovative carbon nanotube via interconnect architectures. Appl. Phys. Lett. 2007, 91, 252107. [CrossRef]

270. Bauerdick, S.; Linden, A.; Stampfer, C.; Helbling, T.; Hierold, C. Direct wiring of carbon nanotubes for integration in nanoelectromechanical systems. J. Vac. Sci. Technol. B Microelectron. Nanometer. Struct. 2006, 24, 3144-3147. [CrossRef]

271. Banerjee, K.; Srivastava, N. Are carbon nanotubes the future of VLSI interconnections? In Proceedings of the 39th conference on Design automation-DAC '02 2006, San Francisco, CA, USA, 24-28 July 2006; p. 809.

272. Naeemi, A.; Meindl, J.D. Carbon nanotube interconnects. In Proceedings of the 2007 International Symposium on Physical Design, ISPD '07, Austin, TX, USA, 18-21 March 2007; p. 77.

273. Chai, Y.; Chan, P.C.H. High electro-migration-resistant copper/carbon nanotube composite for Interconnect application. In Proceedings of the 2008 IEEE Electron Devices Meeting, San Francisco, CA, USA, 15-17 December 2008.

274. Kordás, K.; TóTh, G.; Moilanen, P.; Kumpumäki, M.; Vähäkangas, J.; Uusimäki, A.; Vajtai, R.; Ajayan, P.M. Chip cooling with integrated carbon nanotube microfilm architectures. Appl. Phys. Lett. 2007, 90, 123105. [CrossRef]

275. Li, J.; Ye, Q.; Cassell, A.; Ng, H.T.; Stevens, R.; Han, J.; Meyyappan, M. Bottom-up approach for carbon nanotube interconnects. Appl. Phys. Lett. 2003, 82, 2491-2493. [CrossRef]

276. Collins, P.G. Nanotubes for Electronics. Sci. Am. 2000, 283, 67-69. [CrossRef]

277. Westervelt, R.M. APPLIED PHYSICS: Graphene Nanoelectronics. Science 2008, 320, 324-325. [CrossRef]

278. Potsma, H.W.C.; Teepen, T.; Yao, Z.; Grifoni, M.; Dekker, C. Carbon Nanotube Single-Electron Transistors at Room temperature. Science 2001, 293, 76-79.

279. Chen, Z.; Sippel-Oakley, J.; Tang, J.; Wind, S.J.; Solomon, P.M.; Appenzeller, J.; Lin, Y.-M.; Rinzler, A.G.; Avouris, P. An Integrated Logic Circuit Assembled on a Single Carbon Nanotube. Science 2006, 311, 1735. [CrossRef]

280. Wang, C.; Chien, J.-C.; Takei, K.; Takahashi, T.; Nah, J.; Niknejad, A.M.; Javey, A. Extremely Bendable, High-Performance Integrated Circuits Using Semiconducting Carbon Nanotube Networks for Digital, Analog, and Radio-Frequency Applications. Nano Lett. 2012, 12, 1527-1533. [CrossRef] [PubMed]

281. Appenzeller, J.; Lin, Y.-M.; Knoch, J.; Chen, Z.; Avouris, P. Comparing Carbon Nanotube Transistors-The Ideal Choice: A Novel Tunneling Device Design. IEEE Trans. Electron Devices 2005, 52, 2568-2576. [CrossRef]

282. Parnell, A.J. Nano-technology and the potential for a renewable solar future. Nanotechnol. Percept. 2011, 7, 180-187. [CrossRef]

283. Rasmussen, L. Electroactivity in Polymeric Materials; Springer Science \& Business Media: Berlin, Germany, 2012; 162 p.

284. Jørgensen, M.; Carlé, J.E.; Søndergaard, R.R.; Lauritzen, M.; Dagnæs-Hansen, N.A.; Byskov, S.L.; Andersen, T.R.; Larsen-Olsen, T.T.; Böttiger, A.P.; Andreasen, B.; et al. The state of organic solar cells-A meta-analysis. Sol. Energy Mater. Sol. Cells 2013, 119, 84-93. [CrossRef]

285. Chauhan, A.K.; Gusain, A.; Jha, P.; Koiry, S.P.; Saxena, V.; Veerender, P.; Aswal, D.K.; Gupta, S.K. Graphene composite for improvement in the conversion efficiency of flexible poly 3-hexyl-thiophene: [6,6]-phenyl C71 butyric acid methyl ester polymer solar cells. Appl. Phys. Lett. 2014, 104. [CrossRef]

286. Guldi, D.M.; Rahman, G.M.A.; Prato, M.; Jux, N.; Qin, S.; Ford, W. Single-Wall Carbon Nanotubes as Integrative Building Blocks for Solar-Energy Conversion. Angew. Chem. 2005, 117, 2051-2054. [CrossRef]

287. Neuville, S. Advanced ta-C coatings with up-dated fundamentals for energy production efficiency. Mater. Day Proc. 2018, 5, 13816-13826. 
288. Casas, C.D.L.; Li, W. A review of application of carbon nanotubes for lithium ion battery anode material. J. Power Sources 2012, 208, 74-85. [CrossRef]

289. Banerjee, A.; Ziv, B.; Levi, E.; Shilina, Y.; Luski, S.; Aurbac, D. Single-Wall Carbon Nanotubes Embedded in Active Masses for High-Performance Lead-Acid Batteries. J. Electrochem. Soc. 2016, 163, A1518-A1526. [CrossRef]

290. Fu, K.; Yildiz, Ö.; Bhanushali, H.; Wang, Y.; Stano, K.; Xue, L.; Zhang, X.; Bradford, P.D. Aligned Carbon Nanotube-Silicon Sheets: A Novel Nano-architecture for Flexible Lithium Ion Battery Electrodes. Adv. Mater. 2013, 25, 5109-5114. [CrossRef]

291. Barghi, S.H.; Tsotsis, T.T.; Sahimi, M. Chemisorption, physisorption and hysteresis during hydrogen storage in carbon nanotubes. Int. J. Hydrog. Energy 2014, 39, 1390-1397. [CrossRef]

292. Dillon, A.C.; Jones, K.M.; Bekkedahl, T.A.; Kiang, C.H.; Bethune, D.S.; Heben, M.J. Storage of hydrogen in single-walled carbon nanotubes. Nature 1997, 386, 377-379. [CrossRef]

293. Safa, S.; Mojtahedzadeh, L.M.; Fathollahi, V.; Kakuee, O.R. Investigating hydrogen storage behavior of carbon nanotubes at ambient temperature by ion beam analysis. Nano 2010, 5, 341-347. [CrossRef]

294. Yuca, N.; Karatepe, N. Hydrogen storage in single-walled carbon nanotubes purified by microwave digestion method. World Acad. Sci. Eng. Technol. 2011, 79, 605-610.

295. Valenti, G.; Boni, A.; Melchionna, M.; Cargnello, M.; Nasi, L.; Bertoni, G.; Gorte, R.J.; Marcaccio, M.; Rapino, S.; Bonchio, M.; et al. Co-axial heterostructures integrating palladium/titanium dioxide with carbon nanotubes for efficient electrocatalytic hydrogen evolution. Nat. Commun. 2016, 7. [CrossRef] [PubMed]

296. Gong, K.; Du, F.; Xia, Z.; Durstock, M.; Dai, L. Nitrogen-Doped Carbon Nanotube Arrays with High Electrocatalytic Activity for Oxygen Reduction. Science 2009, 323, 760-764. [CrossRef] [PubMed]

297. Zhang, S.J.; Shao, T.; Kose, H.S.; Karanfil, T. Adsorption of aromatic compounds by carbonaceous absorbents: A comparative study on granular activated carbon, activated carbon fibers, and carbon nanotubes. Environ. Sci. Technol. 2010, 44, 6377-6383. [CrossRef] [PubMed]

298. Apul, O.G.; Karanfil, T. Adsorption of synthetic organic contaminants by carbon nanotubes: A critical review. Water Res. 2015, 68, 34-55. [CrossRef] [PubMed]

299. Polikarpova, N.P.; Zaporotskova, I.V.; Vilkeeva, D.E.; Polikarpov, D.I. Sensor properties of carboxyl-modified carbon nanotubes. Nanosyst. Phys. Chem. Math. 2014, 5, 101-106.

300. Pötschke, P.; Andres, T.; Villmow, T.; Pegel, S.; Brünig, H.; Kobashi, K.; Fischer, D.; Häussler, L. Liquid sensing properties of fibers prepared by melt spinning from polylactic acid containing multi-walled carbon nanotubes. Compos. Sci. Technol. 2010, 70, 343-349. [CrossRef]

301. Hashim, D.P.; Narayanan, N.T.; Romo-Herrera, J.M.; Cullen, D.A.; Hahm, M.G.; Lezzi, P.; Suttle, J.R.; Kelkhoff, D.; Muñoz-Sandoval, E.; Ganguli, S.; et al. Covalently bonded three-dimensional carbon nanotube solids via boron induced nanojunctions. Sci. Rep. 2012, 2. [CrossRef] [PubMed]

302. Mikael, P.E.; Nukavarapu, S.P. Functionalized Carbon Nanotube Composite Scaffolds for Bone Tissue Engineering: Prospects and Progress. J. Biomater. Tissue Eng. 2011, 1, 76-85. [CrossRef]

303. Balavoine, F.; Schultz, P.; Richard, C.; Mallouh, V.; Ebbesen, T.W.; Mioskowski, C. Helical Crystallization of Proteins on Carbon Nanotubes: A First Step towards the Development of New Biosensors. Angew. Chem. Int. Ed. 1999, 38, 1912-1915. [CrossRef]

304. Fasano, M.; Chiavazzo, E.; Asinari, P. Water transport control in carbon nanotube arrays. Nanoscale Res. Lett. 2014, 9. [CrossRef] [PubMed]

305. Hesami, M.; Bagheri, R.; Masoomi, M. Combination effects of carbon nanotubes, MMT and phosphorus flame retardant on fire and thermal resistance of fiber-reinforced epoxy composites. Iran. Polym. J. 2014, 23, 469-476. [CrossRef]

306. Lv, J.; Leong, E.S.; Jiang, X.; Kou, S.; Dai, H.; Lin, J.; Liu, Y.J.; Si, G. Plasmon-Enhanced Sensing: Current Status and Prospects. Hindawi J. Nanomater. 2015, 16. [CrossRef]

307. Lamb, H. Sandvik Reveals 3D Printed Diamond Composite; Engineering and Technology: Hertfordshire, UK, 2019.

(C) 2019 by the author. Licensee MDPI, Basel, Switzerland. This article is an open access article distributed under the terms and conditions of the Creative Commons Attribution (CC BY) license (http://creativecommons.org/licenses/by/4.0/). 